QE
701

5666

SI Ref.

Textural Observations on Some Living Species of Planktonic Foraminifera

\title{
RICHARD CIFELLI
}




\title{
SERIES PUBLICATIONS OF THE SMITHSONIAN INSTITUTION
}

Emphasis upon publication as a means of "diffusing knowledge" was expressed by the first Secretary of the Smithsonian. In his formal plan for the Institution, Joseph Henry outlined a program that included the following statement: "It is proposed to publish a series of reports, giving an account of the new discoveries in science, and of the changes made from year to year in all branches of knowledge." This theme of basic research has been adhered to through the years by thousands of titles issued in series publications under the Smithsonian imprint, commencing with Smithsonian Contributions to Knowledge in 1848 and continuing with the following active series:

\author{
Smithsonian Contributions to Anthropology \\ Smithsonian Contributions to Astrophysics \\ Smithsonian Contributions to Botany \\ Smithsonian Contributions to the Earth Sciences \\ Smithsonian Contributions to the Marine Sciences \\ Smithsonian Contributions to Paleobiology \\ Smithsonian Contributions to Zoology \\ Smithsonian Studies in Air and Space \\ Smithsonian Studies in History and Technology
}

In these series, the Institution publishes small papers and full-scale monographs that report the research and collections of its various museums and bureaux or of professional colleagues in the world of science and scholarship. The publications are distributed by mailing lists to libraries, universities, and similar institutions throughout the world.

Papers or monographs submitted, for series publication are received by the S.mithsonian Institution Press, subject to its own review for format and style, only through departments of the various Smithsonian museums or bureaux, where the manuscripts are given substantive review. Press requirements for manuscript and art preparation are outlined on the inside back cover.

\author{
S. Dillon Ripley \\ Secretary \\ Smithsonian Institution
}




\title{
Textural Observations on Some Living Species of Planktonic Foraminifera
}

\author{
Richard Cifelli \\ ISSUED \\ MAR 181982 \\ MITHSONIAN PUBLICATIOI
}

SMITHSONIAN INSTITUTION PRESS

City of Washington

1982 


\begin{abstract}
A B S T R A C T
Cifelli, Richard. Textural Observations on Some Living Species of Planktonic Foraminifera. Smithsonian Contributions to Paleobiology, number 45, 45 pages, 15 plates, 1982.-Wall textures of 11 species of spinose and quasi-spinose planktonic foraminifera collected in plankton tows from the North and Equatorial Atlantic have been studied with the scanning electron microscope. Illustrations and descriptions of these textures are given herein. During the ontogeny of the individual the chamber wall thickens and the texture is modified in various forms. Thickening occurs by the addition of sheet-like laminations and clustering of crystallites that generally develop into ridges among the pores. Patterns of textural development vary among species, but there are some common trends.
\end{abstract} Official publication date is handstamped in a limited number of initial copies and is recorded
in the Institution's annual report, Smithsonian Year. Series cover Design: The trilobite Phacops
rana Green.

\footnotetext{
Library of Congress Cataloging in Publication Data Cifelli, Richard.

Textural observations on some living species of planktonic foraminifera.

(Smithsonian contributions to paleobiology ; no. 45)

Bibliography: p.

Supt. of Docs. no.: SI 1.30:45

1. Foraminifera-Atlantic Ocean. 2. Foraminifera-Development. 3. Foraminifera-Morphology. 4. Ultrastructure (Biology) 5. Protozoa-Development. 6. Protozoa-Morphology. 7. Protozoa-Atlantic Ocean. I. Title. II. Series.

QE701.S56 no. 45 [QL368.F6] 560s 81-607840 [592.1'304471] AACR2
} 


\section{Contents}

Introduction $\ldots \ldots \ldots \ldots \ldots \ldots \ldots \ldots \ldots \ldots \ldots \ldots$

Collections and Methods $\ldots \ldots \ldots \ldots \ldots \ldots \ldots \ldots \ldots \ldots \ldots \ldots \ldots \ldots$

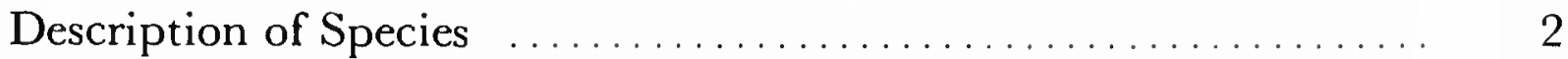

Acknowledgments ............................... 2

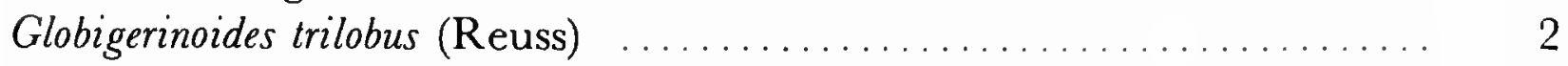

Globigerinoides ruber (d'Orbigny) $\ldots \ldots \ldots \ldots \ldots \ldots \ldots \ldots \ldots \ldots \ldots \ldots$

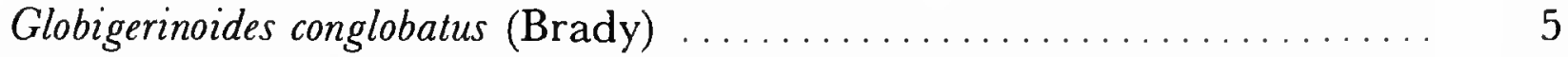

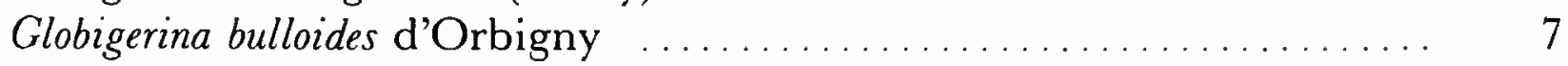

Globigerina dutertrei d'Orbigny $\ldots \ldots \ldots \ldots \ldots \ldots \ldots \ldots \ldots \ldots \ldots \ldots$

Globigerina pachyderma (Ehrenberg) ...................... 9

Globigerina incompta Cifelli ............................ 9

Globigerina egelida Cifelli and Smith $\ldots \ldots \ldots \ldots \ldots \ldots \ldots \ldots \ldots \ldots \ldots$

Globigerinella aequilateralis (Brady) .......................... 11

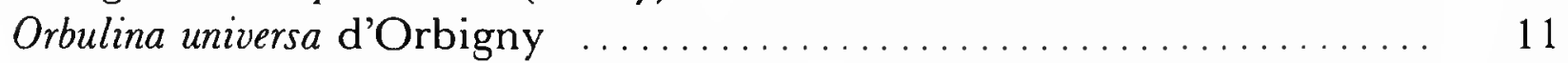

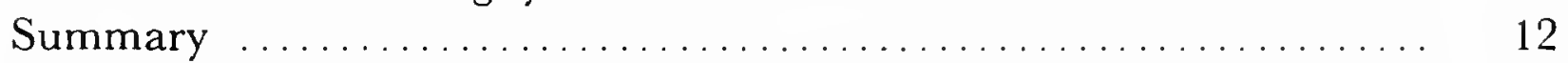

Appendix: Station Data for Illustrated Specimens . . . . . . . . . . . . . 13

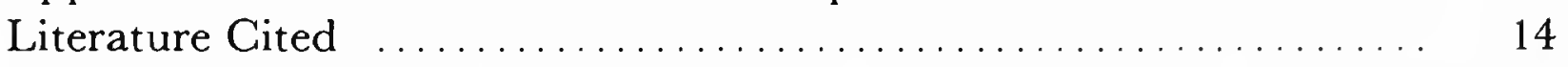

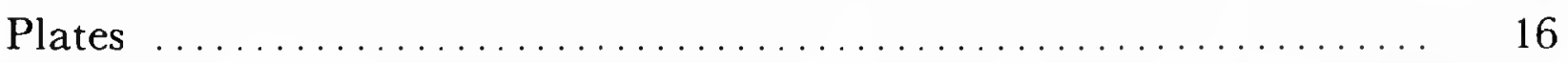





\title{
Textural Observations on Some Living Species of Planktonic Foraminifera
}

\author{
Richard Cifelli
}

\section{Introduction}

Even before the SEM came into common use Parker (1962) and Lipps (1966) recognized the conservative nature of surface texture and its importance in classifying the planktonic foraminifera. In the past dozen or so years a number of SEM studies have been made on the texture of recent and fossil foraminifera. Saito and others (1976) re-evaluated several planktonic genera and families on the basis of surface structural details and spines revealed by SEM studies. Steineck and Fleisher (1978) proposed guidelines for an evolutionary classification of the Globigerinacea using wall texture as a principle key to reconstruction of phylogenies. The problem, however, is that a lot still remains to be learned about the formation and variability of wall texture before a truly satisfactory natural classification can be achieved. Many more sufficiently magnified SEM illustrations of well-preserved specimens with descriptions are needed. In this respect it is important, as pointed out by Hemleben and others (1977), to study live material collected in plankton tows so that features due to ontogenetic growth can be clearly separated from those that may be caused by post-depositional processes. Of course, specimens collected live in plankton tows are most Natural History, Smithsonian Institution, Washington, D.C. 20560. often dead when actually studied, so that the calcifying process cannot be observed. Nevertheless, plankton populations often contain various growth stages of species that yield important ontogenetic information and provide opportunities for interpretations of textural development, as was ably demonstrated by Hemleben (1969). Some aspects of calcification in cultured specimens of Globigerinoides sacculifer ( $=G$. trilobus) have been observed by Bé (1980).

In this study Scanning Electron Micrographs (SEM) and descriptions of representative recent spinose and quasi-spinose planktonic species collected in plankton tows from the North and Equatorial Atlantic are provided. Spinosity, actually, is variable, sometimes obscure and difficult to determine. Not only are spines often destroyed in the process of plankton towing, but spines may be discarded or resorbed during or just prior to gametogenesis (Bé and others, 1977; Bé, 1980) or during ontogeny (Adshead, 1980). Also, spines may be weakly formed or aborted in the course of development, as appears to be the case with Globigerina dutertrei, or may not develop at all, as possibly in $G$. pachyderma. However, all of the species included herein show some textural affinities that seem to set them apart from the smoothwalled globorotalids, although taxonomic judgment is withheld at this time, and no revisions or realignments of species are proposed. The present 
work is meant to serve as a descriptive base for the study and evaluation of surface textures of species found in the fossil record.

The spinose Hastigerina pelagica has not been considered herein because that species has been thoroughly dealt with by Bé (1967), Hemleben (1969), and others. In addition, H. pelagica, although spinose, has a wall surface that appears unique among planktonic foraminifera. Sphaeroidinella dehiscens, which is spinose in its early stages, has been described in detail by Bé and Hemleben (1970).

Collections and Methods.-The illustrated specimens were collected during various cruises of Woods Hole Oceanographic Institution research vessels in the North and Equatorial Atlantic. (Station data for the specimens are given in the Appendix.) Collections were made by obliquely towing a $3 / 4$ meter, number $10(0.158 \mathrm{~mm})$ net for one half to one hour, mostly from 0 to 200 meters depth. (Towing depths at which the studied specimens were recovered are given in the Appendix.)

Concentrates of foraminifera were obtained by igniting plankton samples in a furnace at a temperature of $500^{\circ} \mathrm{C}$. After rinsing in water, suites of specimens were mounted on glass cover slips with Elmer's glue. The specimens were then coated with gold palladium and viewed with the Cambridge Mark-II A and S4-10 scanning electron microscopes.

All illustrated specimens are housed in the foraminiferal collections of the National Museum of Natural History. They have been retained on their original glass cover slips and do not bear catalog numbers.

Descriptions of Species.-Since the purpose of this work is descriptive and no revisions are proposed, the generic designation of species is conservative, following traditional, common usage. Thus, for example, the species dutertrei, incompta, and pachyderma, which Kennett and Srinivisan (1980) would place in Neogloboquadrina, are retained in Globigerina. Morphologic discussions of species and synonomies are given in Cifelli (1965), and Cifelli and Smith (1970). The species are arranged in the order that they were studied.

Acknowledgements. - I am grateful to $\mathrm{Mr}$. Walter R. Brown and Mss. Mary-Jaques Mann and Susann Braden for their operation of the scanning electron microscopes.

\section{Globigerinoides trilobus (Reuss) \\ Plates 1-3}

A very early ontogenetic stage is shown in Plate 1 (figure 1). The glassy test is uniformly thin and smooth throughout, with no textural development except for the few scattered spines. The lack of wall reinforcement of any of the chambers suggests that all of the chambers formed at nearly the same time. At this stage the test still has a globigerine open umbilicus, with a thin lip around the apertural area. Pores are minute (0.001-0.002 $\mathrm{mm}$ ) and irregularly shaped (Plate 1: figure la). They are closed by a tough membrane that begins to rupture in some places. There is a total absence of ridges around the pores and the surface is covered with a very fine veneer. Beneath the veneer the test is minutely granular, as can be seen in the lower left hand corner of Plate 1 (figure 1a), where the veneer has worn away. Spines are already developed at this early ontogenetic stage, but they are widely dispersed and are not oriented around the pore areas. They rise directly from the test surface, unsupported by spine bases or buttresses.

Delicate juvenile specimens of the kind described above are rarely encountered, as the walls of earlier chambers are quickly reinforced by some wall thickening. Most often it is only on the last-formed chamber that initial calcified stages are found. Globigerinoides trilobus reinforces its chambers more rapidly than most other planktonic species and even the last chamber is seldom found in a delicate state.

The chamber wall is reinforced or thickened both by the addition of sheet-like laminations and by the development of terraces around the pores (Hemleben, 1969). That is, the calcite may 
be added as a uniform envelope around the chamber, or as discrete, terraced piles of crystallites arranged in a geometric fashion around the pores. The terraced structures are commonly referred to as pore funnels or honeycomb structure. Some sheet-like development proceeds first, as a means of quickly reinforcing the test, but terracing also occurs at an early stage and, in fact, a clear distinction between the two processes cannot always be made. At an early ontogenetic stage the sheet-like laminations may produce an undulating surface that corresponds to the basic configuration of the later-formed, honeycombed, funneled terraces around the pores (Hemleben, 1969). Terraces of crystallites first form at the bases of the spines, then extend laterally and interconnect to form pentagonally or hexagonally shaped funnels or honeycombs around the pores. The resulting texture, however, never achieves the degree of geometric perfection seen in other organisms, such as the radiolaria.

Sometimes the terracing process is "retarded" and the wall is thickened almost entirely by sheetlike development. Sac-like (sacculiferan) chambers, especially, seem little inclined to develop terracing. Plate 1 (figure 2a) shows the surface of a sac-like chamber, and the wall, which is relatively firm, has been reinforced almost entirely by sheet-like envelopments. Terracing around the spines is poorly developed and only a bare configuration of honeycombing around the pores is visible. A well-formed honeycomb structure has not been observed on any sac-like chambers.

Stages in development of terracing and honeycomb structure are shown in Plate 1 (figures 3 and 4) and Plate 2 (figures 1 and 2). On the last chamber of Plate 1 (figure 3 ) the outlines of pore funnels are just visible. Spines are sparsely distributed but show some orientation to the pores, particularly in the upper part of the chamber. Terracing has barely commenced, and calcite has been added in sheet-like laminations, with the undulations in the sheets forming a "template" for pore funnel development. Early formed terracing can be seen on the final chamber of Plate 1 (figure 4, 4a). Thin platelets have accumulated around the bases of the spines and extend laterally to form an imperfect hexagonal outline. Only three of the corners of the hexagon are occupied by spines but heaps of granules or platelets occur at the other corners, the sites of future spine development. The existing spines form with formation of the chamber, and extend through the wall from the previous chamber, according to the observations of Hemleben (1969).

Accumulations of granules occur both on the terraced plates and on the area surrounding the pores (Plate 1: figure 4a). The granules are loosely packed and distributed somewhat irregularly, and suggest that some sheet-like deposition accompanied formation of terraces, but from a precipitating matrix insufficiently concentrated in calcite to form a continuous sheet. Pores are mostly open, but some remnants of pore membranes persist.

Further terrace development is shown in Plate 2 (figure 2, 2a). There are four well-developed and one incipient spine bases connected by tiers of crystallites that form roughly pentagonal patterns around the pores. The tiers have grown vertically rather than obliquely, so that open, flat spaces surround the pores. These flat spaces of the test are thick and firm, as can be seen at the rims of the pores. The texture is finely granular, but unlike Plate 1 (figure 4, 4a), the granules are tightly packed and evenly distributed. Here it appears the precipitating matrix was saturated and deposited its calcite as a continuous uniform sheet. The same fine, granulose texture also occurs on the tiered crystallites. Pores are mostly open, but some remnants of membranes still persist.

Terrace development and thickening around the pore area is subject to a certain amount of variation, as can be seen by comparing figure 1 , $1 \mathrm{a}, 1 \mathrm{~b}$ with figure 2, $2 \mathrm{a}$ in Plate 2. Figure $1 \mathrm{a}$ shows a portion of an $n$ (last-formed) chamber. Terraces are partially formed, with three to five spines surrounding the pores, which are completely open. As in Plate 1 (figure 4a) growth of terraces has been vertical, and the areas immediately around the pores are not terraced. However, compared with this figure the pore area of 
Plate 2 (figure 1a) is relatively thin, and apparently there has been a "retardation" of sheet-like development. The surface is dark and smooth, probably due to a membraneous cover. Plate 2 (figure $1 \mathrm{~b}$ ) is from the $\mathrm{n}-2$ chamber of the same individual and shows fully developed terraced structure. Here, the typical hexagonal honeycomb pattern or pore funnel development is seen. Six spines occupy the corners around the pores and they are completely connected by terraced platelets. Also, the platelets have grown obliquely to the rims of the pores, so that the pore areas are truly funnel-shaped. A less perfectly shaped honeycomb pattern is shown in Plate 3 (figure 1a), which is the $\mathrm{n}-2$ chamber of another specimen. Terraced platelets are well developed and form deep, completely closed ridges around the pores. However, the full complement of spines is not achieved, with only four or five of them occupying the corners of the ridges. Also, growth of platelets has been essentially vertical, so that the pore areas are cylindrical rather than funnel-shaped.

The calcifying process in Globigerinoides trilobus does not end with the development of honeycomb structure. A later stage of development is shown in Plate 3 (figure $2 a-c$ ). Coarse knobs have formed at the corners of the ridges and spread outward, more or less obliterating the original, fine-terraced structure. The rounded but platy knobs superficially resemble pustules seen in Globorotalia species. However, globorotalid pustules have laminated structures (Hemleben, 1975) that were not observed in these knobs. During growth the knobs show little regard for pore openings and partially enclose them. Spines are mostly resorbed or discarded and remain concentrated only in the sutural and apertural areas. At low magnification (Plate 3: figure 2) the $\mathrm{n}$ chamber retains a honeycomb appearance, but at high magnification it can be seen that the coarse knobs have already begun to form. Spines have disppeared, and ridge corners, though still identifiable, are coarsely knobbed and growing towards each other. Late calcification may also result in the development of coarse, euhedral crystals (Bé and Hemleben, 1970). Bé (1980) reported that heavy calcification in this species occurs during gametogeneses.

\section{Globigerinoides ruber (d'Orbigny)}

Plates 4, 5

Globigerinoides ruber closely resembles $G$. trilobus in textural development. One difference is that $G$. ruber tends to be spinier, or at least this species retains spines longer during ontogeny. Among examined populations of the two species, greater concentrations of spines were almost always observed on $G$. ruber. Also, $G$. ruber is generally less calcified. Terraced ridges and pore funnels are developed, but the ridges are less inclined to connect than in $G$. trilobus, so that the honeycomb texture is generally more open than in G. trilobus. This difference, actually, can be observed in the light microscope and in the past some taxonomists have used honeycomb texture as a distinguishing character of $G$. trilobus. However, a reliable taxonomic distinction cannot be made on this basis because the difference from $G$. ruber is only a matter of degree, and there is overlap in development. Excellent honeycomb texture occasionally occurs in $G$. ruber, as shown in the individuals figured herein. Late calcifying stages of G. trilobus, where the spines are lost and the ridges are covered with coarse knobs, were not found in G. ruber.

Globigerinoides ruber shows variable contrast in the amount of calcification between last-formed and previous chambers. For example, in Plate 4 (figure 1 and especially figure 2) the last-formed chambers are thin and texturally immature, while the previous chambers have well-developed terraced ridges. In plate 5 (figure 1) there is less contrast between chambers, as terraced ridges on the penultimate chamber are only partially formed. Hemleben (1969) figured a specimen in which all chambers appear newly formed (pl. 10: fig. 1). Chamber addition and wall thickening seem to be essentially separate calcifying processes, or at least lack a fixed-time relationship. Sometimes a chamber is added relatively rapidly, at other times it is delayed while the organism reinforces its existing chambers. 
Incipient ridge formation is shown in Plate 4 (figure 1a), where a thin-walled, last-formed chamber has been reinforced by some sheet-like deposition. Small humps surround the pores in well-formed, hexagonal patterns. Spines are scarce, but they occupy the corners of the incipient ridges. The bases of the spines are buttressed by platelets, but the platelets have not yet spread laterally along the ridges. All of the surface is covered by a smooth, gray veneer, and most of the pores are open. Initial development of platelets on the incipient ridges is shown by Hemleben (1969, pl. 10: fig. 7; pl. 14: fig. 7).

On the penultimate chamber of the specimen on Plate 4 (figure 1b) terraced ridges are fully developed and form a honeycomb texture. There is a full compliment of spines, with six spines occupying the corners of each of the hexagonally formed ridges around the pores. On one of the spine bases (just upper left of center in Plate 4: figure $1 \mathrm{~b}$ ) there is a cavity where the spine has broken off and fallen out. Cavities in spinal bases are commonly found in specimens from fossil sediments, and are an important means of determining whether fossil species were truly spinose. The terraced platelets have grown obliquely towards the pores and form true pore funnels. There are no granules and the surface appears smooth, except for the terraced texture of the platelets.

Penultimate chambers with less-developed pore ridges are shown in Plate 4 (figure 2) and Plate 5 (figure 1). The spine bases are well reinforced by terraced platelets that interconnect laterally, though not completely. The growth of ridges has been irregular, resulting in uneven, undulating ridge surfaces. In Plate 5 (figure 1) there has been only slight extension of the platelets towards the pore rims. Pore funnels are not developed. There is greater extension in Plate 4 (figure 2a), but the pore areas are more cylindrical than funnel-shaped. Under the light microscope, the latter surface textures, which are more common in mature specimens of Globigerinoides ruber than the specimen figured in Plate 4 (figure 1), appear quasi-honeycomb. Four to five spine bases surround each of the pores, but in Plate 4 (figure 2a) the spines have mostly disappeared. The tips of the spine bases are rounded and knob-like, similar to the later stages of $G$. trilobus, but are not nearly as coarse. In Plate 5 (figure 1) the spines are still mostly intact, and even where they are broken off, the remaining parts can be seen in the spine bases. On both of these specimens, as in Plate 4 (figure $1 \mathrm{~b}$ ), the platelets are single crystallites with no granular cover. Even at magnifications of $\times 5000$ the surfaces appear smooth.

Plate 5 (figure 2) shows a specimen that is well calcified and with few spines. Broad outlines of pore ridges and spine bases are visible, but they are incompletely joined, especially in the area below the aperture. At low magnification the texture of this specimen appears the same as that of the previous ones, but a coarse granular surface becomes visible when the magnification is increased (Plate 5: figure 2b). The terraced platelets are completely obscured by a thick deposit of coarse, well-packed granules. The granules are uniformly distributed over the pore areas and the former sites of ridges and spine bases, which now appear as knob-like projections. These projections are distributed rather irregularly and are disjointed. Honeycomb structure was probably weakly developed before the process was interrupted by a rain of granules.

\section{Globigerinoides conglobatus (Brady)}

\section{Plates 6, 7; Plate 8: figure 1}

Before discussing the stages of textural development, a note should be interjected about morphologic development of Globigerinoides conglobatus. Throughout most of its ontogeny this species adds its chambers trochospirally, and has an open umbilicus, as in Globigerina species (Cifelli, 1965). In fully formed individuals the coiling shifts towards the umbilical area and the final chamber overlaps the umbilicus, resulting in a low primary aperture. This ontogenetic change provides a convenient means of distinguishing morphologically immature forms from adult forms independent of specimen size, which is variable. Therefore, in $G$. 
conglobatus it is possible to make some comparisons between textural and morphological maturity.

In general, morphologically adult forms are also texturally well developed, with fully formed terraced ridges and spines (Plate 7: figure 2). However, the thickening rate is variable, and morphologically immature forms (i.e., individuals with an open umbilicus) are often thicker walled than morphologic adults. An example is shown in Plate 7 (figure 3), where the immature, open umbilicus specimen has begun development of a ropy texture on its previous chambers and appears encrusted. The texture of this surface is more mature than the surface of the adult specimen in Plate 7 (figure 2). Accelerated calcification may inhibit further morphologic development, so that a full, morphologically adult stage is never reached. For example, many encrusted foraminifera found in bottom sediments, such as Globigerina pachyderma, tend to be small, suggesting that growth has been inhibited. To what degree the differences in calcifying rates are due to intrinsic genetic variability or environmental factors is not known.

Globigerinoides conglobatus thickens its wall both by the addition of sheet-like laminations and by the development of terraced ridges, as in $G$. trilobus and $G$. ruber. A very small, morphologically and texturally immature individual is shown in Plate 6 (figure 1). The specimen is very spiny, but the spines are incompletely distributed around the pores. Texture appears no better developed in the early chambers than in the last-formed chamber, and the whole surface of the test is flat. However, some sheet-like thickening has occurred in the previous chambers, as multiple laminations are visible at the rims of the pores at high magnification (Plate 6: figure 1b); the laminations are not visible in the last-formed chamber (Plate 6: figure la). On all chambers the terraces have formed at the bases of the spines, but the terraces do not yet extend laterally to form ridges. Many of the pores remain closed, particularly in the last-formed chamber.

Further textural development is shown in Plate 6 (figure 2, 2a). No terracing has occurred on the last chamber of this individual and the surface is flat, with a few scattered spine bases. The previous chambers are very spiny and terraced ridges are partially developed. Outlines of the terraces are weakly formed and considerable open space remains around the pore areas. The wall of the previous chambers (Plate 6: figure 2a) has been reinforced by sheets, as can be seen at the pore rims.

Plate 6 (figure 3) and Plate 7 (figure 1) show more advanced textural development. Terraced ridges are well formed and in some cases are hexagonally shaped. There is also oblique growth of the terraced ridges towards the pore rims so that many of the pore areas are funnel shaped. Spines are unequal in size and incompletely developed; they do not occur at all of the corners of the terraced ridges. However, the spines are well reinforced by terraced platelets, shown in Plate 6 (figure 3a). Cracks have formed in the buttress, and the spine begins to separate. During the postmortem process spines fall out, leaving cavities at the sites of the spine bases as in other spinose species.

Fully developed, terraced structure can be seen in Plate 7 (figure 2, 2a) which shows a morphologically adult individual with an overlapping final chamber. The completely closed, terraced ridges extend obliquely to the pore rims to form distinct pore funnels. Terraced ridges are as well developed in the final chamber as in the previous chambers. Elongate spines appear only in the apertural areas, but the whole specimen is still spinose. At high magnification (Plate 7: figure 2a) the spine bases are visible on all of the chambers.

The encrusting phase of calcification can be seen in Plate 7 (figures 2, 2a and 3, 3a). The individual shown in Plate 7 (figure 3 ) is no longer spinose, except in the apertural and sutural areas. Over the remainder of the surface, on all chambers, coarse, knob-like structures have grown over the spine bases or corners of the terraced ridges. These knobs are composed of platy crystallites and superficially resemble the pustules of Globorotalia species. They grow mostly vertically, but 
also extend laterally and encroach on the pore areas. As mentioned above, this encrusted individual is still morphologically immature, as it has an open umbilicus, with no overlapping final chamber. A heavily encrusted form is shown in Plate 8 (figure 1, 1a). The knob-like structures cover most of the pore area in the previous chambers. They are composed of large, platy crystallites with sharp faces arranged vertically to the pores. One of the features of calcification in planktonic foraminifera is an increase in size of crystallites with growth, as noted previously herein and by Hemleben (1969) and others. A similar tendency has been noted among benthonic foraminifera (Conger, Green, and Lipps, 1977).

In Globigerinoides conglobatus granular surfaces that occasionally occur in $G$. trilobus and $G$. ruber have not been found. However, it is suspected that examination of more specimens would reveal presence of these surfaces. A very light scattering of minute granules can be seen in the sutural areas of Plate 6 (figures 2,3) and Plate 7 (Figure 2).

Globigerinoides conglobatus seems to show a greater tendency towards heavy calcification than any other planktonic species. Thick-walled or encrusted forms were found in virtually every plankton tow examined.

\section{Globigerina bulloides d'Orbigny}

$$
\text { Plate 8: figures 1, 2; Plate } 9
$$

Except in newly formed chambers, the wall of Globigerina bulloides is highly porous. Pores are small $(0.002-0.005 \mathrm{~mm})$ but densely packed in an irregular, clustered pattern. Occasional pores are almost joined (Plate 9: figure 1a). Seldom is there sufficient space around the pores to allow formation of individually closed ridges or funnels. The shape of the pores tends to be much less regular than in Globigerinoides. In this species high porosity is achieved some time after the formation of the chamber. On newly formed chambers the pores are truly minute $(0.0005 \mathrm{~mm})$ and widely spaced (Plate 8: figure 2a). At low magnification new chambers appear almost imperforate and contrast sharply in appearance with earlier formed chambers. As the wall becomes reinforced and texturally developed the porosity of the lastformed chamber increases. Eventually, the size and density of the pores become the same as those of previously formed chambers, as shown in Plate 8 (figure 3) and Plate 9 (figure 1).

Newly formed chambers, although weak, tend to be pliable, so that the wall is sometimes partially indented or collapsed (Plate 8: figure 2). The surface of the wall is slightly undulating but essentially smooth, and the spines are widely scattered. In Plate 9 (figure 2) the last chamber is newly formed but firm and undented. All of the scattered spines are completely without buttresses, but appear to be of two separate generations, following the interpretation of Hemleben (1969). On the upper right hand side of Plate 9 (figure 2b) the spines extend directly from the surface and probably project through the wall from the previous chamber. These spines, therefore, very likely were present at the time of formation of the chamber. Conversely, the spine in the lower left corner rises from a rather amorphous heap that forms a platform on which the spine has grown. This spine developed after formation of the chamber. Additional heaps that provide bases for growth of spines are shown in Plate 9 (figure 2a). There are also smaller, sinuous undulations that mark the course of future ridge development. Some thickening by sheet-like lamination in this chamber is indicated by the uniformly depressed positions of the membraneous covers in all of the pores (Plate 9: figure 2b).

The spine buttresses and ridges that are built during textural development are like those in Globigerinoides. That is, the buttresses and ridges are composed of small, flat platelets neatly arranged in terraces (Plate 8: figure 3a; Plate 9: figure 2c). However, unlike Globigerinoides, individual pores in this species are not the centers of ridge development. Occasional ridges may enclose single pores, as in Plate 8 (figure 3a), but such instances are exceptional. Scott (1974) noted 
similar development in specimens of this species recovered from bottom sediments. The ridges generally develop in sinuous paths among the pores, sometimes covering them (Plate 9: figures 1a, 3a). There is no geometric pattern, as two or more pores are surrounded by the heterogeneously shaped ridges. Similarly, the placement of spines shows no special relationship to the pores and are distributed in an irregular fashion along the ridges.

Globigerina bulloides seems to have a basically similar kind of textural development to Globigerinoides, but the ridge pattern is much more erratic. The failure of $G$. bulloides to form a neat honeycomb structure may be caused by the fact that porosity is late in development, so that pores may still be forming when ridges begin to build. Also, the pores are densely packed and may not provide sufficient space for ridge enclosure. Scott (1974) ascribes pore size and regularity of distribution as causative factors in honeycomb structure.

Spines shed easily in this species, and hollow spine bases are common in individuals brought up in plankton tows (Plate 9: figure 3a).

\section{Globigerina dutertrei d'Orbigny}

$$
\text { Plates 10, 11; Plate 12: figure } 1
$$

Large, widely spaced pores cover the chamber surfaces and each of the pores is surrounded by pore ridges in texturally mature forms. The surface closely resembles the honeycomb structure of Globigerinoides species except for the seeming absence of spines in Globigerina dutertrei. Actually, $G$. dutertrei does produce spine-like projections, but they are intermittent in occurrence and aborted. As the chamber calcifies, spines are quickly engulfed by the surrounding ridges and never develop fully. As a result, the test surface of $G$. dutertrei appears non-spinose when viewed under ordinary magnifications. However, at magnifications of about $\times 1000$, a search of chambers that are not too highly calcified usually reveals some stunted spines or remnants of them. Srinivisan and Kennett (1976) noted spine-like projections on Pleistocene representatives of $G$. dutertrei and called them pseudospines. However, these projections do not differ from spines in other species except that they do not become fully elongate. I prefer to think of them as homologous structures that have been retarded in development.

A relatively immature individual with moderately calcified chambers is shown in Plate 10 (figure 1). On the n-2 chamber (Plate 10: figure 1b) free-standing spines occur on low, wellformed, terraced ridges. The spines are stunted, irregularly sized, and sporadically distributed. Ridge development is more complicated than in Globigerinoides species. They develop partly by terracing around the spine bases, as suggested in Plate 10 (figure 1b). At the same time, however, ridges appear to have an independent development. For example, on the final, weakly calcified chamber of the same individual, strong rib-like undulations occur with little evidence of spines. They are much stronger than the sheet-like undulations in newly formed chambers of Globigerinoides. A rib-like texture is characteristic of newly formed chambers of Globigerina dutertrei. Moreover, on the same newly formed chamber there occur separate spinose and ribbed areas, as in Plate 11 (figure 2a). At the top of the chamber there are spines with no bases, situated on weakly formed, undulating pore ridges. On the lower part of the chamber well-formed ridges without spines occur and run subparallel with each other. It is not clear how these seemingly independent structures combine to form the uniform honeycomb texture seen in mature individuals of $G$. dutertrei.

Another relatively immature individual is shown in Plate 10 (figure 2). On the final chamber rib-like ridges are apparent, while in the previous chambers the ribs appear to coalesce and form an incipient honeycomb structure. The honeycomb is rather smooth surfaced, but remnants of spines can be seen intermittently among the corners of the honeycombs (Plate 10: figure 2a). In this individual the spines appear to have been engulfed quickly by surrounding ridge structures, while development of terraced spine bases is retarded. However, engulfment does not always 
proceed so quickly, and distinct, well-formed terraces around spines are occasionally seen on chambers of mature individuals (Plate 11: figure 1b). Such occurrences tend to be sporadic, as the honeycomb on most chambers of mature individuals has the appearance of crossing, coalescing ridges, with the spines completely obscured except for slight protrusions at the corners of the honeycomb (Plate 11: figure 1c).

The process of spine engulfment is not unique to Globigerina dutertrei. In fact, it probably occurs in all spinose species that experience a late stage of heavy calcification and become encrusted. However, in $G$. dutertrei engulfment apparently occurs at an early stage and the spines never develop fully. This species also tends to calcify more heavily than most planktonic species and in that respect is comparable to Globigerinoides conglobatus. Encrusted individuals are captured fairly commonly in plankton tows. In late stages of calcification the honeycomb structure may be overgrown by coarse, knob-like protrusions, so that the pores are concealed (Plate 10: figure 3). Often, a honeycomb pattern may be retained, but the surface is strewn with coarse, euhedral crystals (Plate 12: figure 1, 1a).

Srinivisan and Kennett (1976) regard the thinand thick-walled forms of this species as separate phenotypes, with the thin-walled form occupying tropical waters and the thick form occupying the cooler subtropical waters. It is possible that the subtropical environment is more conducive to heavy calcification than the tropical environment. However, thick-walled forms are commonly found associated with thin forms in plankton tows from tropical regions. All but one of the specimens of Globigerina dutertrei figured herein are from the Equatorial Atlantic.

\section{Globigerina pachyderma (Ehrenberg)}

Plate 12: figures 2, 3

Previously, there was some doubt that thickwalled forms of Globigerina pachyderma occur in surface waters of the North Atlantic (Cifelli, 1973), but populations of encrusted forms have been recovered recently from the subarctic region (unpublished data). However, thin- and thickwalled populations of this species seem to show little overlap in occurrence, unlike populations of Globigerinoides conglobatus, which generally show a wide range of textural development.

All thin-walled forms observed so far have welldeveloped spine bases and ridges on all chambers. Pores in the thin-walled forms are minute (Plate 12: figure 2, 2a), comparable in size to those in Globigerina bulloides, but widely spaced, as in $G$. incompta. Spinal development appears to be almost completely aborted in this species. The protuberances around the pores are referred to herein as spine bases because they are terraced and similar in appearance to those of spinose species. However, no elongate spines have been observed.

At this stage spine bases (Plate 12: figure 2) in Globigerina pachyderma show very little tendency to spread laterally, so that the ridges are short, stubby, and isolated. In this respect, the texture of this species differs from that of $G$. incompta which, at an equivalent stage of thickening, has elongate ridges and some development of honeycomb pattern (compare Plate 12: figure 2, 2a with Plate 13: figure 2, 2a). Similar textural differences have been observed in representatives of these species from bottom sediments (Olsson, 1976). Accumulations of granules are dispersed in an irregular fashion among the ridges in $G$. pachyderma, as is characteristic of other spinose species.

A thickened, well-calcified form of Globigerina pachyderma is shown in Plate 12 (figure 3, 3a, 3b), where most of the calcification has occurred on the earlier chambers. At this thickened stage, on the $\mathrm{n}$ and $\mathrm{n}-1$ chambers, the spine bases have spread laterally among the pores in a generally irregular fashion, but are partially joined in places to form a quasi-honeycomb pattern. On the earlier chambers all earlier texture is obliterated by coarse, knob-like structures that have grown over the spine bases and covered many of the pores.

\section{Globigerina incompta Cifelli}

Plate 13: figures 1-3

Pores are small, as in Globigerina bulloides (about $0.002-0.005 \mathrm{~mm}$ ), but not so densely packed. On 
newly formed chambers pores are poorly formed and obscure (Plate 13: figure 1). The wall initially thickens by addition of sheet-like laminations and deposition of heaps of calcite arranged irregularly around the pores (Plate 13: figure 1a). In newly formed chambers slight ridge-like undulations can be seen, but the undulations are never as strongly rib-like as in $G$. dutertrei. Some of the calcite heaps apparently are the sites for the later development of spine bases, as suggested in Plate 13 (figure 1b). Calcite granules are often strewn around the pore areas, between the calcitic heaps and spine bases. Terraced ridges are later built around the spine bases and spread laterally, weaving among the pore areas. The ridges occasionally join around the pores and form a quasi-honeycomb structure (Plate 13: figure 2, 2a) that never fully develops, as observed by Srinivisan and Kennett (1976). The pattern of ridge development appears to be intermediate between the regular honeycomb of $G$. dutertrei and the irregular maze of $G$. bulloides. Spine bases develop over most of the surface of $G$. incompta, but growth is arrested and the few visible spines are mostly short and stubby. Under the light microscope this species appears to be "weakly spinose," with most of the spines appearing around the apertural area.

Globigerina incompta does not show a strong tendency for encrustation and most mature individuals encountered in surface waters have a mature texture, but are not particularly thick. However, populations vary and occasional encrusted individuals (Plate 13: figure 3, 3a) will be found. Commonly, the encrusted individuals are small, suggesting that growth has been inhibited by accelerated calcification. As in other planktonic species, the crust is coarsely crystalline and tends to cover the pores.

Kennett and Srinivisan (1980) place Globigerina incompta in synonomy with $G$. pachyderma, because they find thin-walled, left-coiled forms in bottom sediments with the quasi-honeycomb texture characteristic of $G$. incompta. Indeed, the left-coiled form figured by Kennett and Srinivisan (1980, pl. 4: fig. 2) appears reasonably thin-walled and quasi-honeycomb in texture. It is not clear, how- ever, whether such forms are rare or common in bottom sediments. In surface waters, populations of $G$. incompta do contain rare, left-coiled individuals (Cifelli, 1973). Moreover, it has been my experience that left-coiled forms ( $G$. pachyderma) show a much stronger tendency to be thick-walled than the right-coiled forms ( $G$. incompta) in bottom sediments, although of course, there is some overlap. In single assemblages the dense, compact form is always heavily weighted towards left coiling, while the lobulate form is mostly rightly coiled. This difference suggests that the left-coiled and right-coiled forms are independent populations. Difference in distribution of the living forms also suggests mutual independence. In addition, the present study on wall texture indicates that the quasi-honeycomb structure is a later ontogenetic development in $G$. pachyderma than in $G$. incompta. As noted before (Cifelli, 1965, 1973), these forms pose difficult problems and there probably will continue to be differences of opinion as to how they should be treated taxonomically.

\section{Globigerina egelida Cifelli and Smith}

\section{Plate 13: figure 4}

All of the specimens observed have shown about the same degree of textural maturity, with spine bases developed on all chambers. Neither encrusted nor very thin-chambered forms have been found. Pores in this species are relatively large and widely spaced. Free-standing spines are sporadic but fairly common in occurrence. Spiny stublets can be seen around the peripheral margin of the specimen in Plate 13 (figure 4).

The surface texture of Globigerina egelida has a rather unique appearance, with virtually no ridge development around the pores. The spine bases appear as discrete, rounded, knob-like structures dispersed more or less uniformly among the pores. They are composed of interlocking grains that are not as neatly terraced as in other spinose species. Often, these interlocking grains extend over the pore areas, so that the surface has a sutured, etched appearance (Plate 13: figure 4a). 


\section{Globigerinella aequilateralis (Brady)}

Plate 14; Plate 15: figure 1

The textural development of this species is variable, usually showing close affinities with Globigerina bulloides and Orbulina universa, but also on rare occasions resembling Globigerinoides species. In part, that variability seems to be due to differing rates of development of spine bases and ridges with respect to sheet-like laminations. Often, chambers are well thickened, but essentially flat surfaced with spine bases occurring as isolated protrustions (Plate 14: figures 2, 2a and 4, 4a). The spine bases are terraced, as in other spinose species, but do not spread laterally, and remain immature in development. Although relatively thick-walled, development of spine buttresses and ridges has proceeded no farther than in the thinwalled form in Plate 14 (figure 1). In Plate 14 (figure 2) spine bases and ridges remain immaturely developed throughout the test and all chambers are flat. In Plate 14 (figure 4) wellformed ridges occur in the earlier chambers.

When the ridges expand laterally and coalesce, they typically follow an irregular pattern, as in Globigerina bulloides. They weave among the pores in a sinuous fashion, seldom completely enclosing a single pore (Plate 15: figure 1, 1b). Spine bases are irregularly distributed with respect to pores. As thickening proceeds, crystallites of the ridges become coarser and subeuhedral (Plate 15: figure 1a). The ridges also tend to cover the pores, and the spines are resorbed or discarded. In Plate 15 (figure 1a) spinosity is indicated by the hollow openings in the spine bases.

While sheet-like laminations and irregularly dispersed ridges seem to be the common modes of textural development, a honeycomb pattern has also been observed. In Plate 14 (figure 3) the chambers show a well-formed network of ridges that surround individual pores. Spine bases project from the corners of the ridges and the chamber surface is reminiscent of Globigerinoides species. The honeycomb pattern is remarkably uniform, and equally well developed in all chambers of the last whorl. However, chambers of the previous whorls are not honeycombed, except for a small portion of the n-5 chamber. Development of this texture is puzzling. In Globigerinoides species the honeycomb pattern develops by accretion and spreading of the terraced platelets around the pores. The earlier chambers are generally more texturally advanced than the later chambers. In this species it seems that the honeycombed ridges may be deposited almost simultaneously on the chambers of the last whorl, while the embryonic chambers are shielded from deposition.

In this species porosity tends to increase with thickening of the wall, as in Globigerina bulloides. Plate 14 (figure 1) shows an immature individual with thin chambers. The pores are very small (about 0.001-0.002 $\mathrm{mm}$ ) and widely spaced. On mature forms pores reach a size of about 0.006 $0.008 \mathrm{~mm}$ (Plate 14: figure 4a). In Globigerinella aequilateralis pores are more evenly spaced and less densely packed than in Globigerina bulloides.

\section{Orbulina universa d'Orbigny}

Plate 15: figures 2, 3

This species is unique in that it has pores of two distinct sizes. The smaller and more abundant ones are about $0.002 \mathrm{~mm}$, the larger ones about $0.010 \mathrm{~mm}$. However, pore size and density may vary appreciably among populations (Bé, et al., 1976). Another unique feature of this species is that there are no discernable growth stages. Adshead (1967) observed in the laboratory the development of an orbuline form from a grown specimen of Globigerina bulloides, but immature forms, without the final spherical chamber, cannot be recognized for sure in the natural habitat. Bandy (1966) considered Orbulina universa to be polyphyletic.

In all of the specimens examined the final spherical chamber is already well formed and texturally mature (Plate 15: figures 2, 3). The wall is remarkably flat for a spinose species and is often covered with a thin veneer that gives the surface a very smooth appearance (Plate 15: figure $2 \mathrm{a}$ ). Occasionally, however, heaps of rather 
coarse crystallites may cover the surface (Plate 15: figure 3a). This phenomenon has been observed in other spinose species and appears to represent a variable phase in the composition of the precipitating matrix. Inside the margins of the pores the wall is composed of fine, sheet-like lamellae. Spine bases are quite abundant throughout the chamber, but show no tendency to spread laterally. There is a total absence of ridge development and in this respect this species resembles Globigerina egelida. However, the spine bases are short, vertical, terraced buttresses and not rounded mounts as in $G$. egelida. Also, the spine bases are well terraced in $O$. universa and the peculiar sutured pattern of interlocking grains seen in $G$. egelida is lacking. In its flat, smooth surface this species bears some resemblance to Globorotalia species. Spines are discarded readily and are seldom seen on specimens captured in plankton tows. When present, they are very elongate and triradiate at their distal ends (Vilks and Walker, 1974).

\section{Summary}

In the spinose and quasi-spinose species the texture of the chamber wall is modified considerably during the ontogeny of the individuals. Newly formed chambers are very thin and flat walled. At an early stage the chamber may be crossed by undulating ridges that appear to serve as "templates" for future deposition. Pores, at least in some species, are initially minute and covered with a membraneous lid. Some spines are present at the formation of a new chamber, but most of them are added later.

The chamber wall is initially reinforced by sheet-like laminations that cover the entire chamber. Sheet-like laminations continue to be added during development, but the wall is also thickened by discrete pilings of terraced, platy crystallites among the pores. In Globigerinoides the terraced piles originate around the bases of already formed or incipient spines and spread laterally into ridges that join around single pores in a honeycomb pattern. The terraced ridge platelets may grow obliquely and extend to the pore rims, forming funnel-shaped pore areas, or they may grow vertically, resulting in open cylindrical pore areas. Variation from funneled to cylindrical pore areas occur within single species. Globigerina dutertrei has a honeycomb texture similar in appearance to Globigerinoides, but spines are aborted in development and apparently never become elongate. Also, while the ridges sometimes develop from the spine bases, they may also develop independently; the process is not clear.

In Globigerina bulloides the terraced piles also originate at the spine bases but the ridges have a much more irregular pattern. They weave among the pores in a sinuous fashion and only fortuitously enclose single pores. Sometimes the terraced ridges show little or no tendency to spread laterally, so that the spines stand on essentially vertical bases, with most of the intervening wall surface remaining flat, as observed by Olsson (1976).

Other species show intermediate textures. Globigerina incompta has a weakly developed honeycomb texture, with ridges that are generally incompletely joined. In $G$. pachyderma ridges spread laterally only in the later stages of calcification. In early and mature stages the ridges are short and stubby. When $G$. pachyderma individuals reach the encrusting stage there is some spreading of ridges and some development of honeycomb texture. In Orbulina universa, there appears to be virtually no spreading of ridges and the terraced platelets are confined to the vicinity of the bases of the spines, with most of the wall surface remaining smooth and flat. Generally, Globigerinella aequilateralis shows the same kind of surface. However, textural development is variable in this species and on some chambers there is a fully ridged, honeycomb structure. This honeycomb structure may not develop in the same manner as in Globigerinoides. In Globigerina egelida the spine bases are surrounded by knob-like structures composed of interlocking grains. Unlike other species these buttresses do not appear to be terraced.

Deposition of calcite during thickening of the shell seems to occur as a kind of "snowfall" of 
granules from a precipitating matrix. Most often the granules are tightly packed, but their density may vary. Occasionally, it appears that the precipitating matrix is weakly seeded and only a sprinkling of granules are distributed irregularly around the pores.

In the early stages of calicification the granules tend to be very small and resolvable only at magnifications of $\times 2000$ or greater. In the late encrusting stages the size of granules increases appreciably and euhedral, platy crystallites are clearly visible at magnifications of less than $x$ 1000. These crystallites tend to obliterate previously formed textures and even cover the pores. Encrusting appears to be a general phenomenon among planktonic forminifera, but some species show a greater tendency for thickening than others. Globigerinoides conglobatus tends to be the most encrusted form in surface waters, closely followed by Globigerina pachyderma and $G$. dutertrei.

\section{Appendix}

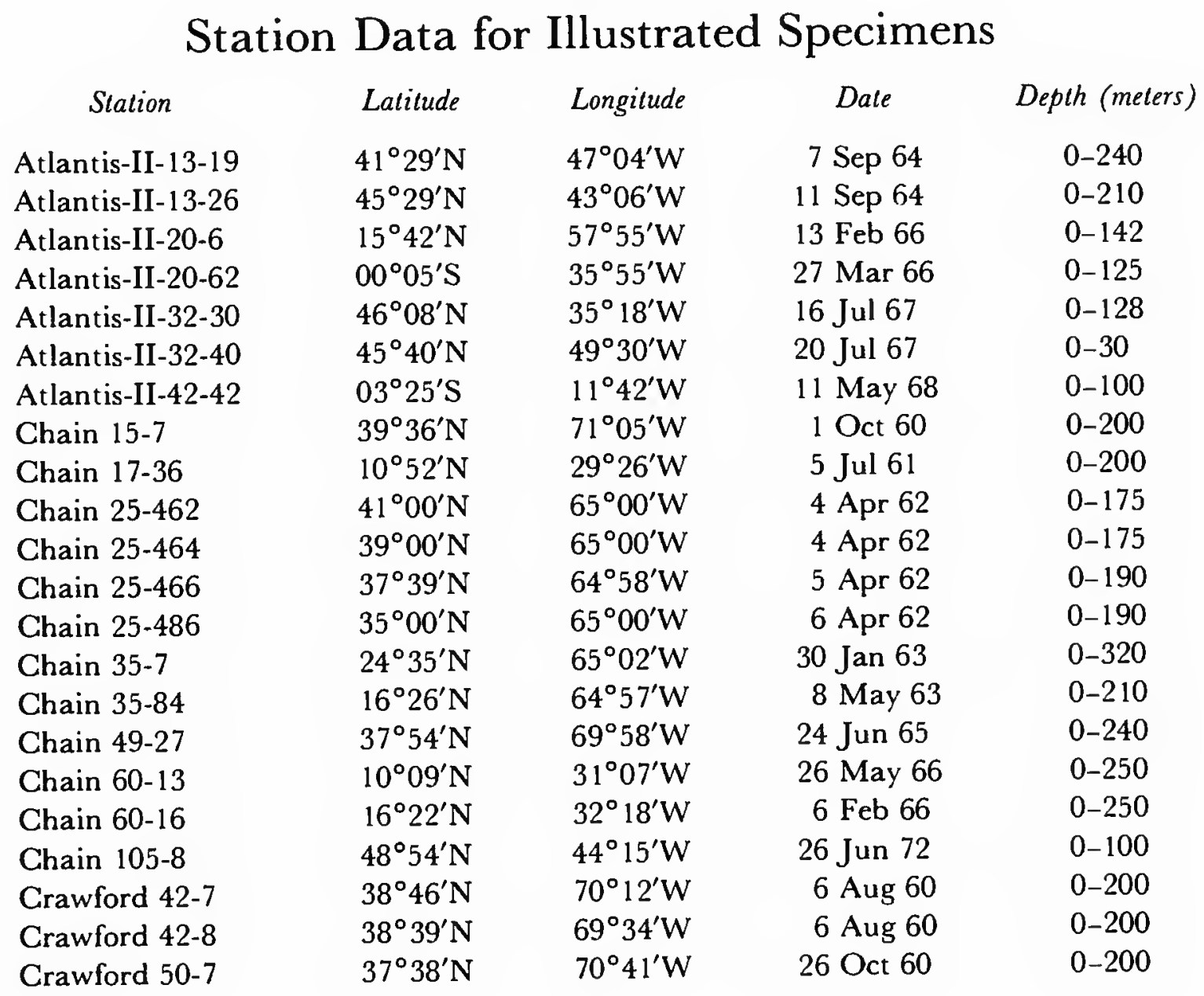




\section{Literature Cited}

Adshead, P. C.

1967. Collection and Laboratory Maintenance of Living Planktonic Foraminifera. Micropaleontology, 13(1): 32-40.

1980. Pseudopodial Variability and Behavior of Globigerinids (Foraminiferida) and Other Planktonic Sarcodina Developing in Cultures. In W. V. Sliter, editor, Studies in Marine Micropaleontology and Paleoecology, a Memorial Volume to Orville L. Bandy, special publication, 19:96-126, plates 1-12. Lawrence, Kansas: Cushman Foundation for Foraminferal Research.

Bandy, O. L.

1966. Restrictions of the Orbulina Datum. MicropaleontolBé, A.W.H. ogy, 12(1):79-86, plate 1 .

1967. Microstructural Evidence of the Close Affinity of Globigerinella Cushman to Hastigerina Thompson. In $\mathrm{P}$ Bronnimann and $\mathrm{H}$. H. Renz, editors, Proceedings of the First International Conference on Planktonic Microfossils, pages 89-91. Geneva.

1980. Ontogenetic Calcification in a Spinose Planktonic Foraminifer, Globigerinoides sacculifer (Brady). Marine Micropaleonlology, 5:283-310, plates 1-9.

Bé, A.W.H., S. M. Harrison, W. E. Freirichs, and M. E. Heiman

1976. Variability in Test Porosity of Orbulina universa d'Orbigny at Two Indian Ocean Localities. In Y. Takayangi and T. Saito, editors, Progress in Micropaleonlology, special publication, pages 1-9, plates 1-3. New York: Micropaleontology Press, American Museum of Natural History.

Bé, A.W.H., and C. Hemleben

1970. Calcification in a Living Foraminifer, Globigerinoides sacculifer (Brady). Neues Jahrbuch für Geologie und Palaontologie Abhandlungen, 134(3):221-234, plates 25-32.

Bé, A.W.H., C. Hemleben, O. R. Anderson, M. Spindler, J. Hacunda, and S. Tuntivate-Choy

1977. Laboratory and Field Observations on Living Planktonic Foraminifera. Micropaleonlology, 23(2): 155-179, plates 1-7.

Cifelli, R.

1965. Planktonic Foraminifera from the Western North Atlantic. Smilhsonian Miscellaneous Collections, 148(4): 1-35, plates 1-9.

1973. Observations on Globigerina pachyderma (Ehrenberg) and Globigerina incompla Cifelli from the North Atlantic. Journal of Foraminiferal Research, 3(4):155166, plates 1-4.

Cifelli, R., and R. K. Smith

1970. Distribution of Planktonic Foraminifera in the Vicinity of the North Atlantic Current. Smithsonian Contributions to Paleobiology, 4:1-52, plates 1-6.

Conger, S. D., H. W. Green II, and J. H. Lipps

1977. Test Ultrastructure of Some Calcareous Foraminifera. Journal of Foraminiferal Research, 7(4):279296, plates 1-9.

Hemleben, C.

1969. Zur Morphogenese Planktonischer Foraminiferen. Zilleliana, 1:91-132, plates 6-18.

1975. Spine and Pustule Relationships in Some Recent Planktonic Foraminifera. Micropaleonlology, 21(3): 334-341, plates 1-2.

Hemleben C., A.W.H. Bé, O. R. Anderson, and S. Tuntivate

1977. Test Morphology, Organic Layers and Chamber Formation of the Planktonic Foraminifer Globorolalia menardii (d'Orbigny). Journal of Foraminiferal Research, 7(1):1-25, plates 1-11.

Kennett, J. P., and M. S. Srivinisan

1980. Surface Ultrastructural Variation in Neogloboquadrina pachyderma (Ehrenberg): Phenotypic Variation and Phylogeny in the Late Cenozoic. In W. V Sliter, editor, Studies in Marine Micropaleonlology and Paleoecology, a Memorial Volume to Orville L. Bandy, special publication, 19:134-162, plates 1-8. Lawrence, Kansas: Cushman Foundation for Foraminiferal Research.

Lipps, J. H.

1966. Wall Structure, Systematics and Phylogeny of Cenozoic Planktonic Foraminifera. Journal of $\mathrm{Pa}$ leonlology, 40(6): 1257-1263.

Olsson, R. K.

1976. Wall Structure, Topography and Crust of Globigerina pachyderma. In Y. Takayanagi, and T. Saito, editors, Progress in Micropaleonlology, special publication, pages 244-257, plates 1-6. New York: Micropaleontology-Press, American Museum of Natural History.

Parker, F L.

1962. Planktonic Foraminiferal Species in Pacific Sediments. Micropaleontology, 8(2):219-254, plates 1-10.

Saito, T., and P R. Thompson

1976. Skeletal Ultramicrostructure of Some Elongate- 
Chambered Planktonic Foraminifera and Related Species. In Y. Takayanagi and T. Saito, editors, Progress in Micropaleonlology, special publication, pages 278-304, plates 1-8. New York: Micropaleontology Press, American Museum of Natural History.

Scott, G. H.

1974. Pustulose and Honeycomb Topography in Globigerinoides trilobus. Micropaleontology, 20(4):466-472, plate 1 .

Srinivisan, M. S., and J. P. Kennett

1976. Evolution and Phenotypic Variation in the Late Cenozoic Neogloboquadrina dutertrei Plexus. In Y.
Takayanagi and T. Saito, editors, Progress in Micropaleontology, special publication, pages 329-355, plates 1-8. New York: Micropaleontology Press, American Museum of Natural History.

Steineck, P. L., and R. L. Fleisher

1978. Towards the Classical Evolutionary Reclassification of the Cenozoic Globigerinacea (Foraminiferida). Journal of Paleontology, 52(3):618-635, plates $1-2$.

Vilks, G., and D. A. Walker

1974. Morphology of Orbulina universa d'Orbigny in Relation to Other Spinose Plantonic Foraminifera. Journal of Foraminiferal Research, 4(1):1-8, plate 3. 


\section{PLATE 1}

1. Globigerinoides trilobus: Very early stage of development with smooth, glassy chambers, scattered spines, and minute pores, $\times 170 ; 1 \mathrm{a}, \mathrm{n}$ chamber partially ruptured, membranes cover pore areas, $\times 2400$. Atlantis-II-20-62.

2. Globigerinoides trilobus: Sacculiferan form, with sac-like final (n) chamber, $\times 80 ; 2 \mathrm{a}, \mathrm{n}$ chamber reinforced mostly by sheet-like development, terraced ridges very weakly formed, $\times 800$. Chain 17-36.

3. Globigerinoides trilobus: Early chambers texturally mature, last chamber newly formed with no pore ridge development, $\times 215$. Atlantis-II-20-6.

4. Globigerinoids trilobus: Last chamber with incipient ridge development; some spines on $\mathrm{n}-1$ chamber triradiate, $\times 200 ; 4 \mathrm{a}, \mathrm{n}$ chamber with early terraced-ridge development, surface covered with loosely packed granules, $\times 800$. Atlantis-11-20-6. 


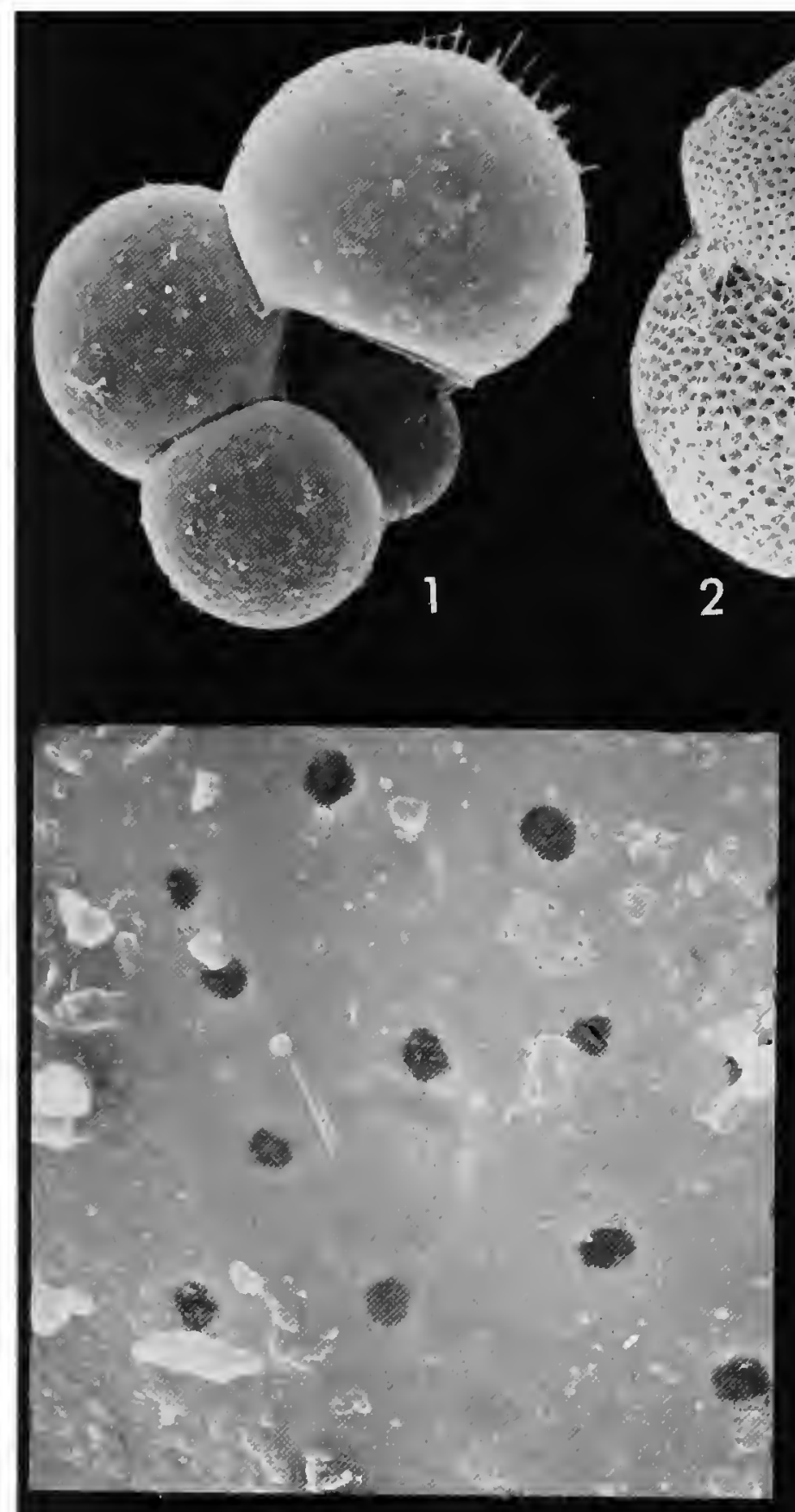

$\mathrm{la}$
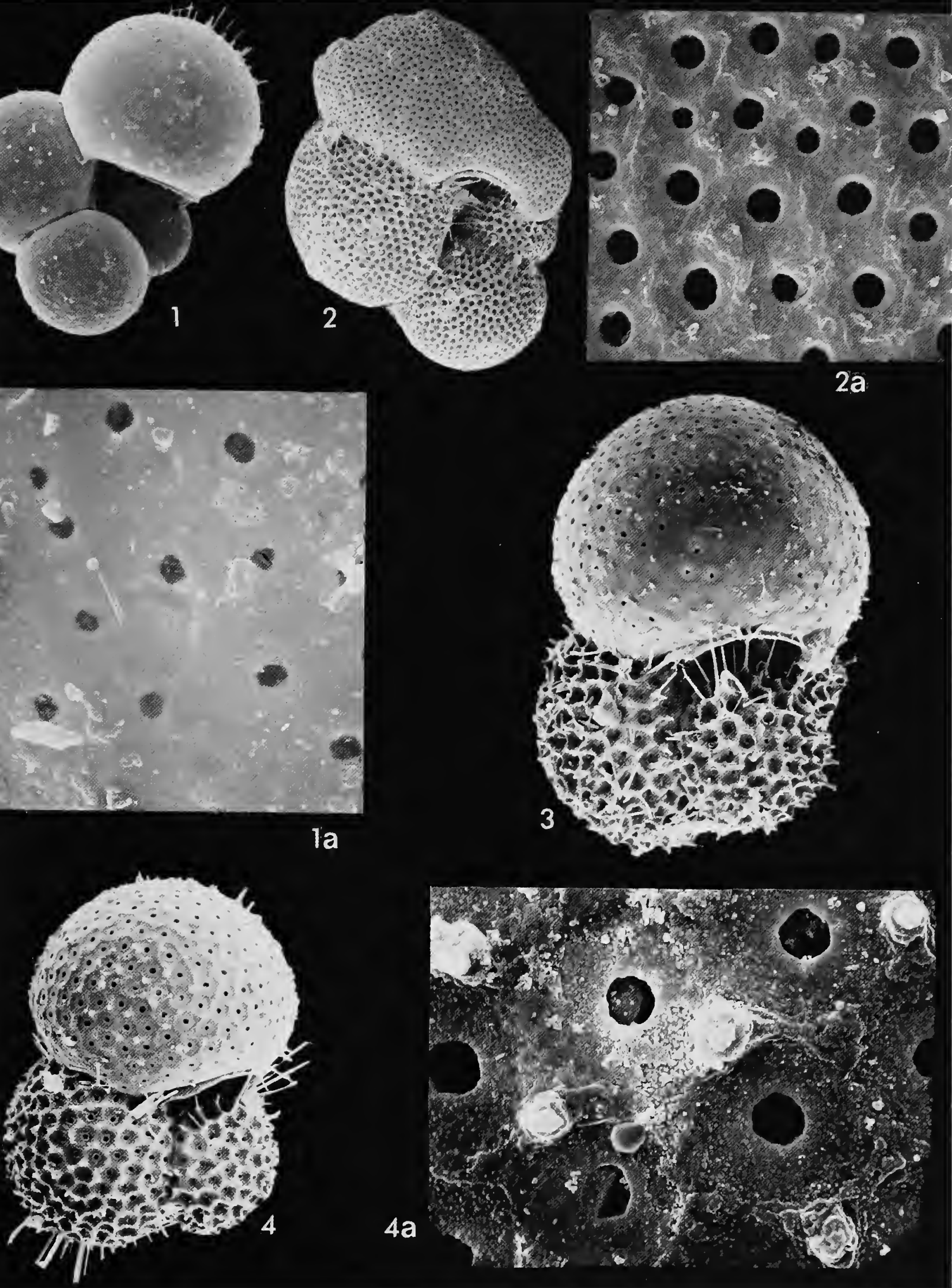

$4 a$
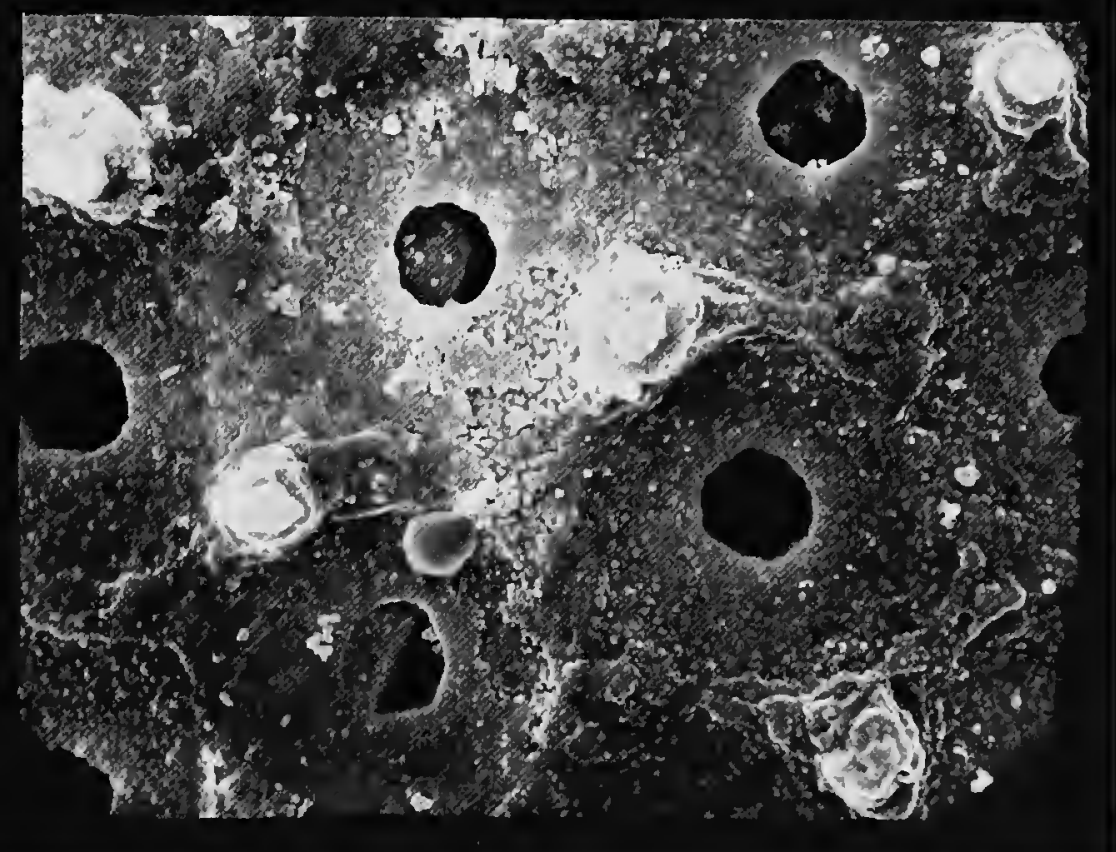


\section{PLATE 2}

1. Globigerinoides trilobus: $\times 125 ; 1 \mathrm{a}, \mathrm{n}$ chamber, terraced platelets around spine bases spread laterally, partially enclosing pore areas, interior of pore areas relatively thin, suggesting retardation of sheet-like accretion, $\times 800 ; 1 \mathrm{~b}, \mathrm{n}-1$ chamber, terraced ridge structure completed, forming hexagonal honeycomb pattern, terraces developed obliquely, extending to margins of pores, resulting in funnel-shaped pore areas (pore funnels), each pore funnel with full complement of spines projecting from corners, $\times 800$. Atlantis-11-42-42.

2. Globigerinoides trilobus: $\times 225 ; 2 \mathrm{a}$, n chamber, terraced tiers have grown vertically, leaving flat open areas around pores, flat areas much thicker than in la, and composed of tightly packed granules, $\times 1600$. Chain 25-486. 


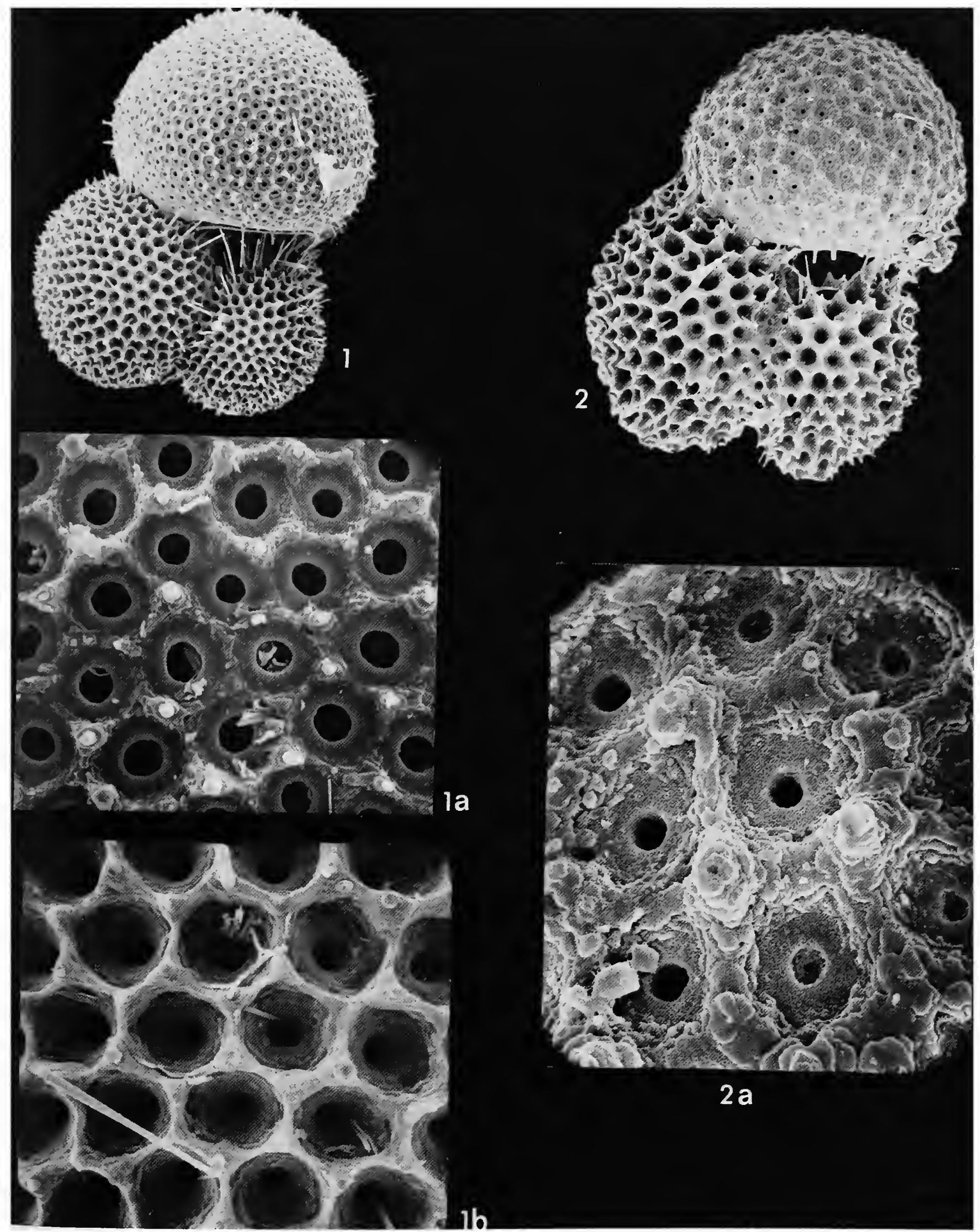




\section{PLATE 3}

1. Globigerinoides trilobus: $\times 125 ; 1 \mathrm{a}, \mathrm{n}-1$ chamber, terraced ridges developed into mature pore funnels, but spines incompletely developed, $\times$ 800. Atlantis-II-42-42.

2. Globigerinoides trilobus: Late stage of calcification, most spines resorbed or discarded, remaining spines confined to apertural and sutural areas, coarse knobs form over spine base areas, $\times 105 ; 2 \mathrm{a}, \mathrm{n}$ chamber, coarse knobs form over original spine bases, but pore funnel structure still visible, $\times 800 ; 2 \mathrm{~b}, \mathrm{n}-1$ chamber, with additional calcification, knobs spread irregularly and obscure original pore funnels, $\times 800 ; 2 \mathrm{c}, \mathrm{n}-2$ chamber, surface acquires ropy texture as knobs continue to grow and spread, rounded knobs platy, resembling pustules of Globorotalia, $\times 800$. Chain 35-84. 


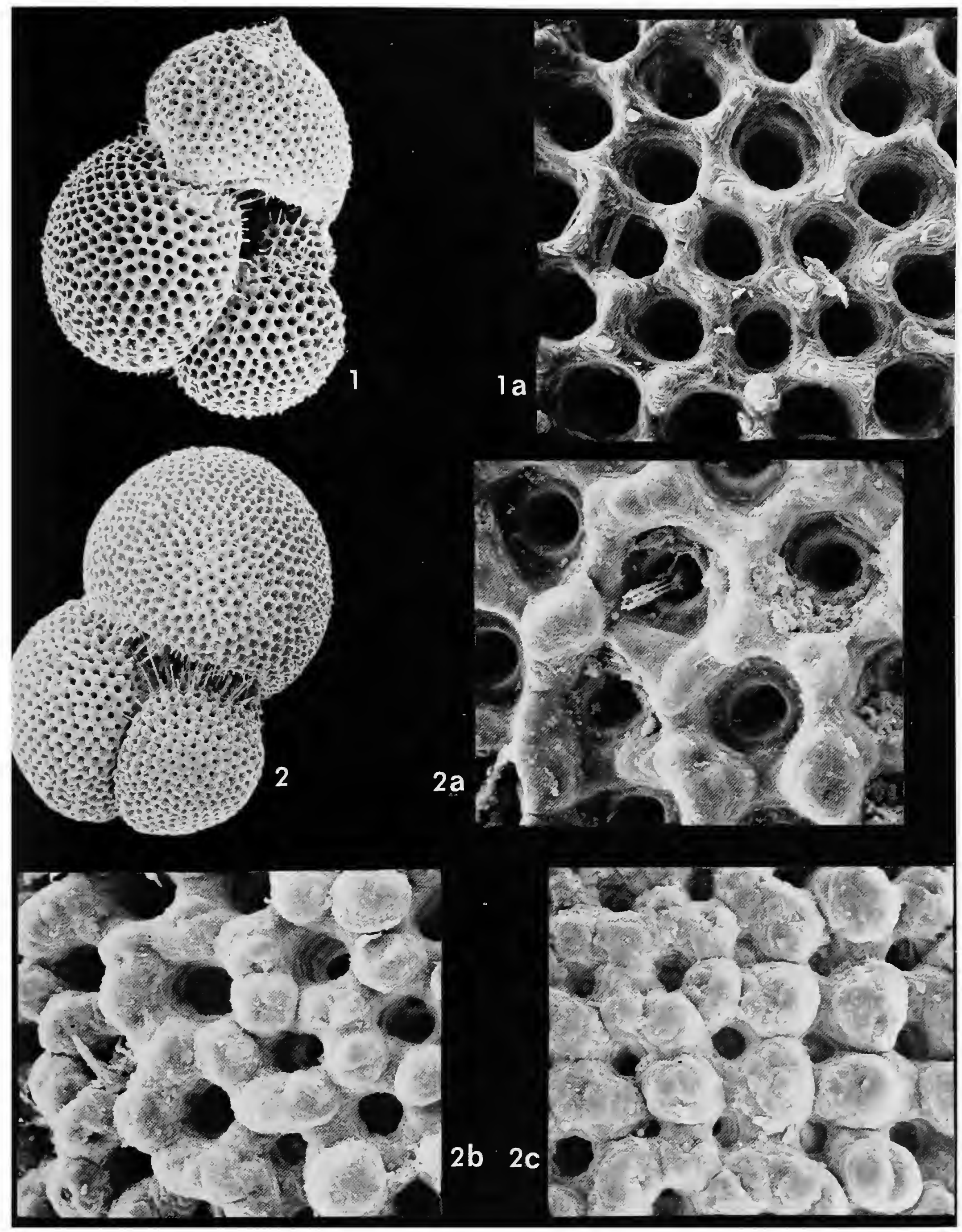




\section{PLATE 4}

1. Globigerinoides ruber: Early chambers texturally mature with well-defined honeycomb structure, last chamber thin and texturally immature, $\times 150 ; 1 \mathrm{a}, \mathrm{n}$ chamber, wall thin, outlines of pore ridges clearly defined, spines few collared by terraced platelets, and occupy ridge corners, $\times 800 ; 1 \mathrm{~b}, \mathrm{n}-1$ chamber, pore funnels excellently formed in hexagonal shapes with all corners of pore ridges occupied by spines, $\times 800$. Atlantis-II-20-62.

2. Globigerinoides ruber: Early chambers texturally mature, but honeycomb structure less geometric than in figure $1, \times 130 ; 2 \mathrm{a}, \mathrm{n}-1$ chamber, $\times 800 ; 2 \mathrm{~b}, \mathrm{n}-1$ chamber enlarged further, ridge platelets mostly vertical so that pore ridges not truly funnel-shaped, $\times 2400$. AtlantisII-20-62. 


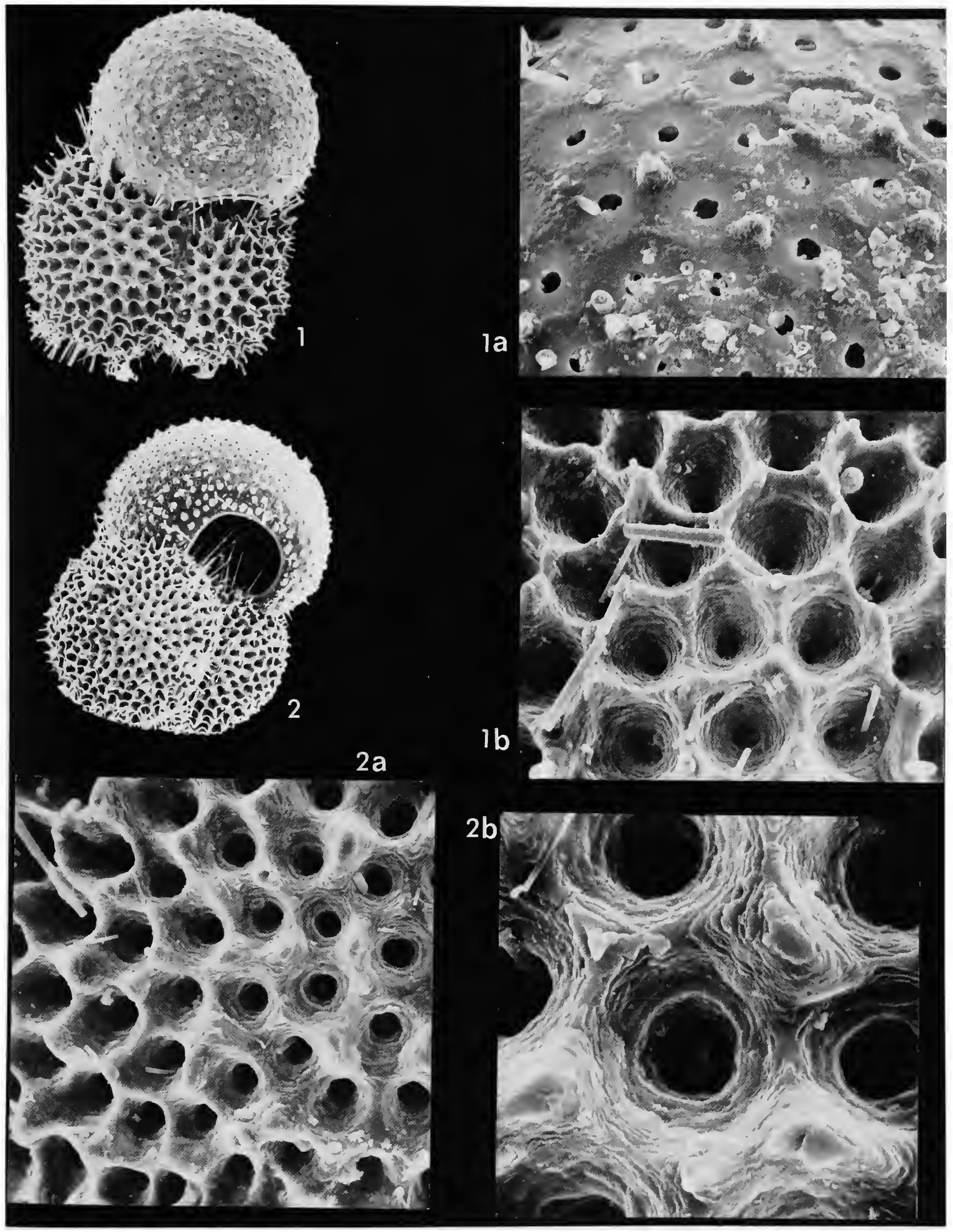




\section{PLATE 5}

1. Globigerinoides ruber: Ridge growth incomplete and texture only partially honeycombed, $\times$ 120; la, n-1 chamber, ridges between spine bases forming uneven undulating surfaces, terraced platelets of ridges vertically, pore area cylindrical rather than funnel-shaped, $x$ $800 ; 1 \mathrm{~b}, \mathrm{n}-1$ chamber, spine enlarged with collar of spine composed of smooth, plate-like crystallites with no granular cover, $\times$ 4000. Chain 49-27.

2. Globigerinoides ruber: All chambers with equivalent textural maturity, but final chamber removed, spines absent, $\times 165 ; 2 \mathrm{a}, \mathrm{n}-2$ chamber, surface coarsely granular, obscuring terraced structure of pore ridges, $\times 800 ; 2 \mathrm{~b}, \mathrm{n}-2$ chamber, surface composed of well-packed granules distributed uniformly over pore area, ridges, and spine bases, no longer bearing spines appearing as knob-like projections, $\times$ 2400. Atlantis-II-13-19. 


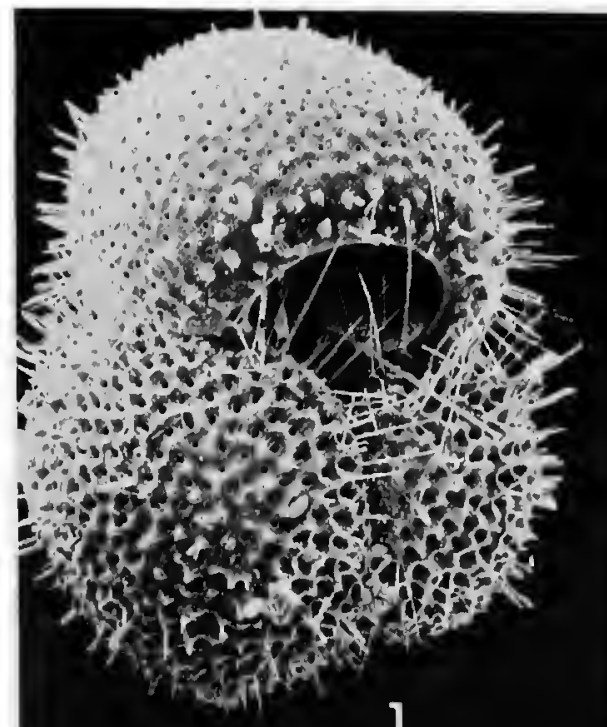

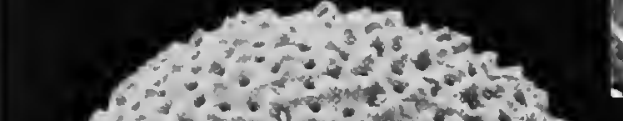
$x^{2}-x^{2}-y^{2}+1$

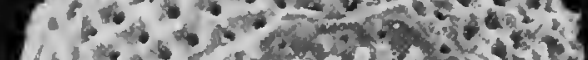

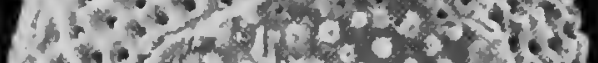

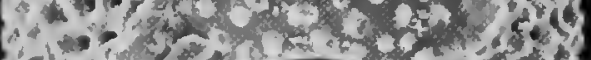

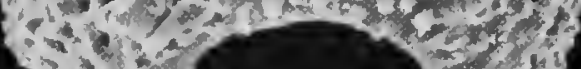
$x^{2}-x^{2}-2$ $4 x^{2}+4 x^{2}+x^{2}-2=$

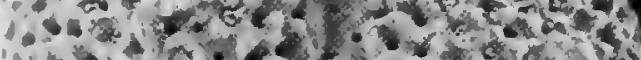

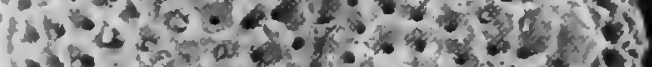

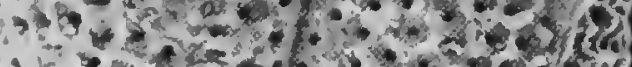

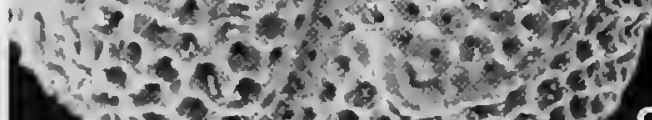

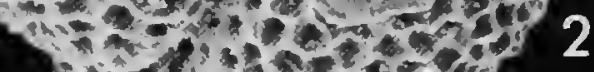

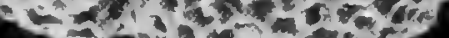
$x^{2}+\ldots+\infty$

$2 b$

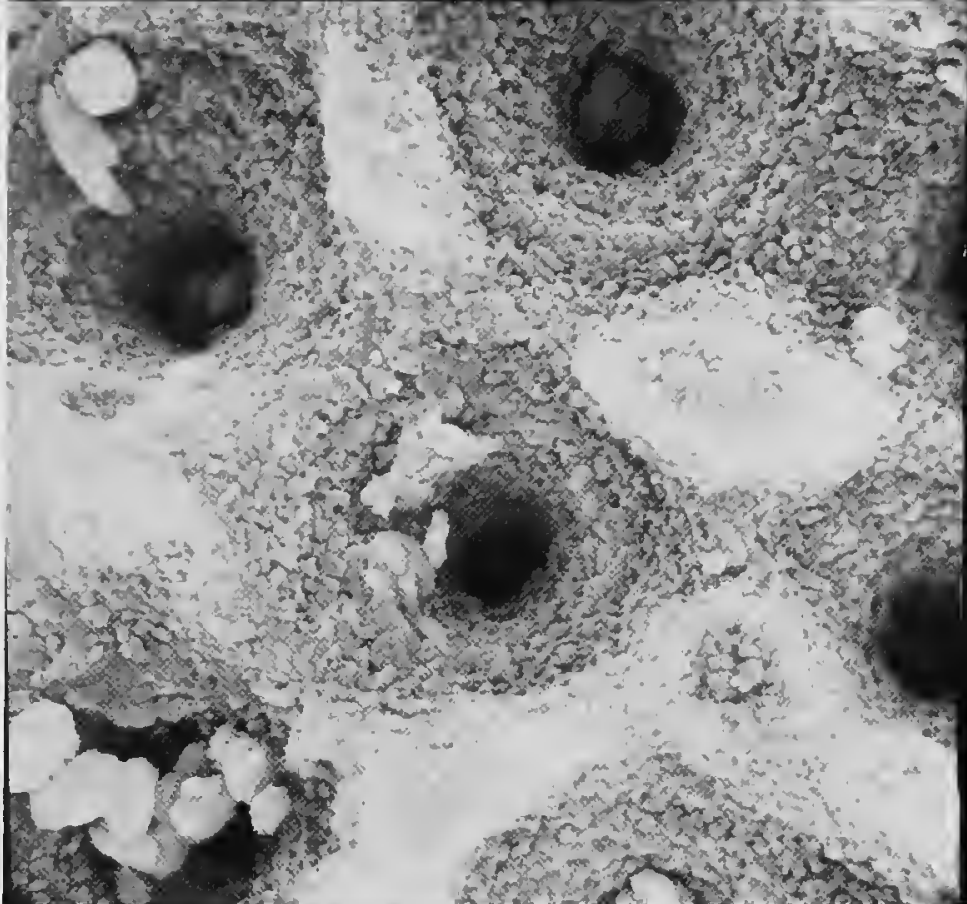

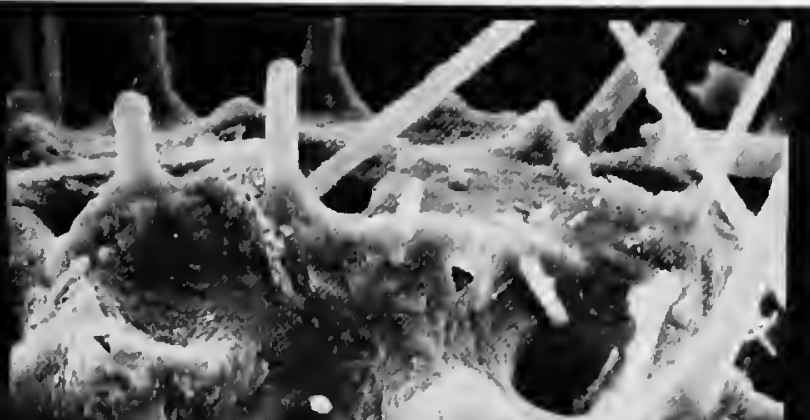

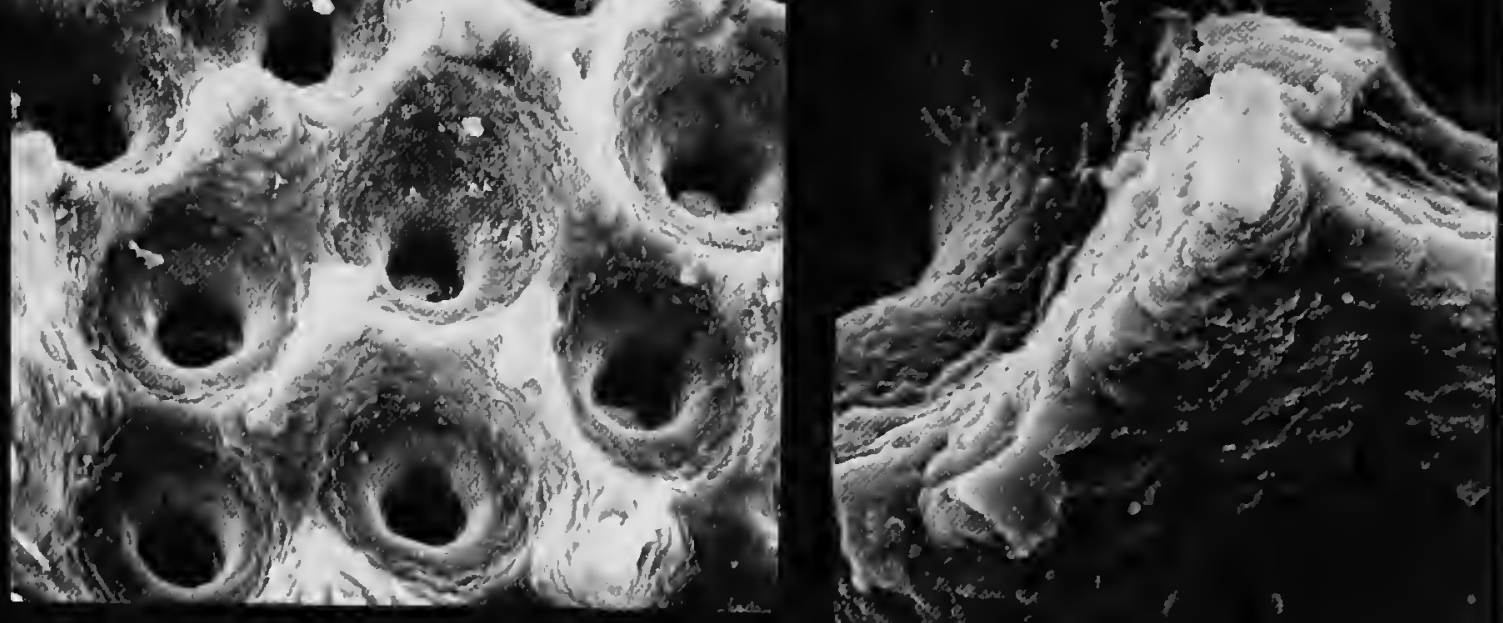

la

$-7=x+3$

16

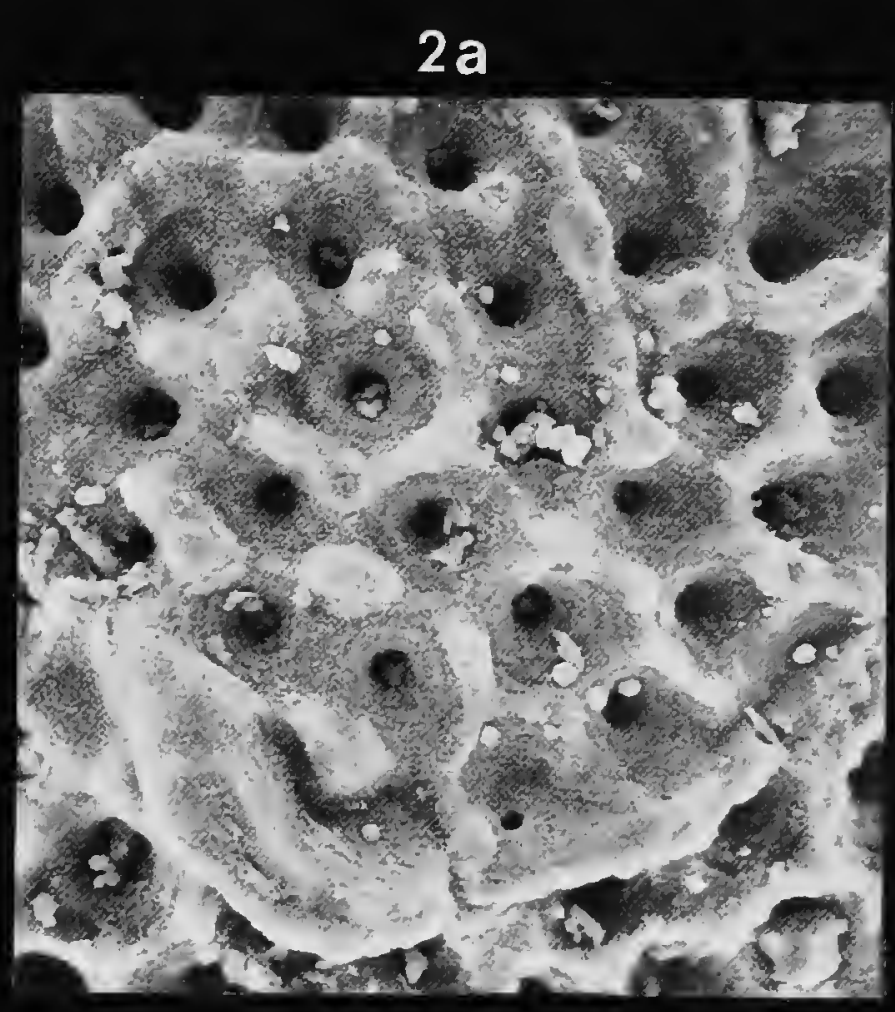




\section{PLATE 6}

1. Globigerinoides conglobalus: Immature individual with very flat, spiny surface on all chambers, all chambers void of pore ridge development; $\times 260 ; 1 \mathrm{a}, \mathrm{n}$ chamber, spine bases reinforced with collars of terraced platelets, dark, membraneous covers, on pores, $\times 1600 ; 1 \mathrm{~b}, \mathrm{n}-2$ chamber reinforced by some sheet-like lamination, shown by multiple laminations at pore rims, $\times$ 4000. Chain 35-7.

2. Globigerinoides conglobatus: Morphologically immature individual with texturally mature earlier chambers, but totally smooth, flat final chamber, $\times 90 ; 2 a, n-1$ chamber, honeycomb texture partially developed, $\times$ 800. Chain 49-27.

3. Globigerinoides conglobatus: Morphologically immature individual with texturally mature honeycomb texture on all chambers, $\times 132 ; 3 a, n-1$ chamber, detail of spine and supporting collar or buttress of platelets $\times 3000$. Chain 35-7. 


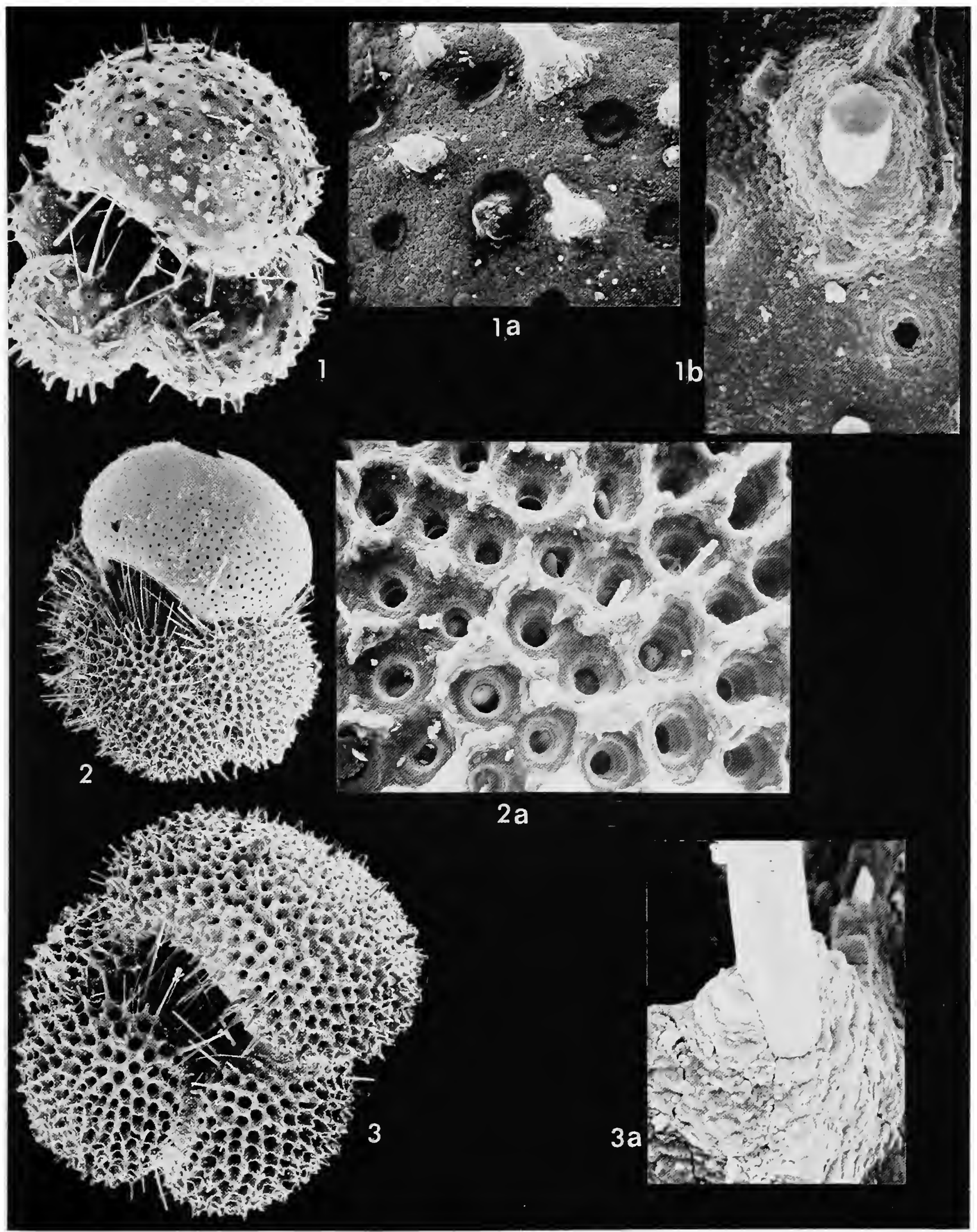




\section{PLATE 7}

1. Globigerinoides conglobatus: Morphologically immature individual with texturally advanced earlier chambers, $\times 85 ; 1 \mathrm{a}, \mathrm{n}-2$ chamber, pore ridges well formed, but without full complement of spines, $\times$ 800. Chain 49-27.

2. Globigerinoides conglobalus: Morphologically mature individual with fully developed honeycomb texture, $\times 120 ; 2 a, n-2$ chamber, pore funnels well formed and accompanied by full complement of spines, $\times 800$. Chain 35-7.

3. Globigerinoides conglobalus: Morphologically immature individual with late stages of textural development, remnants of honeycomb structure still visible in final chamber but completely obliterated in earlier chambers, remaining spines confined to apertural area, $\times 95$; $3 a, n-1$ chamber, former spine bases at corners of pore ridges occupied by coarse, laminated knobs, $\times 800$. Chain 60-13. 

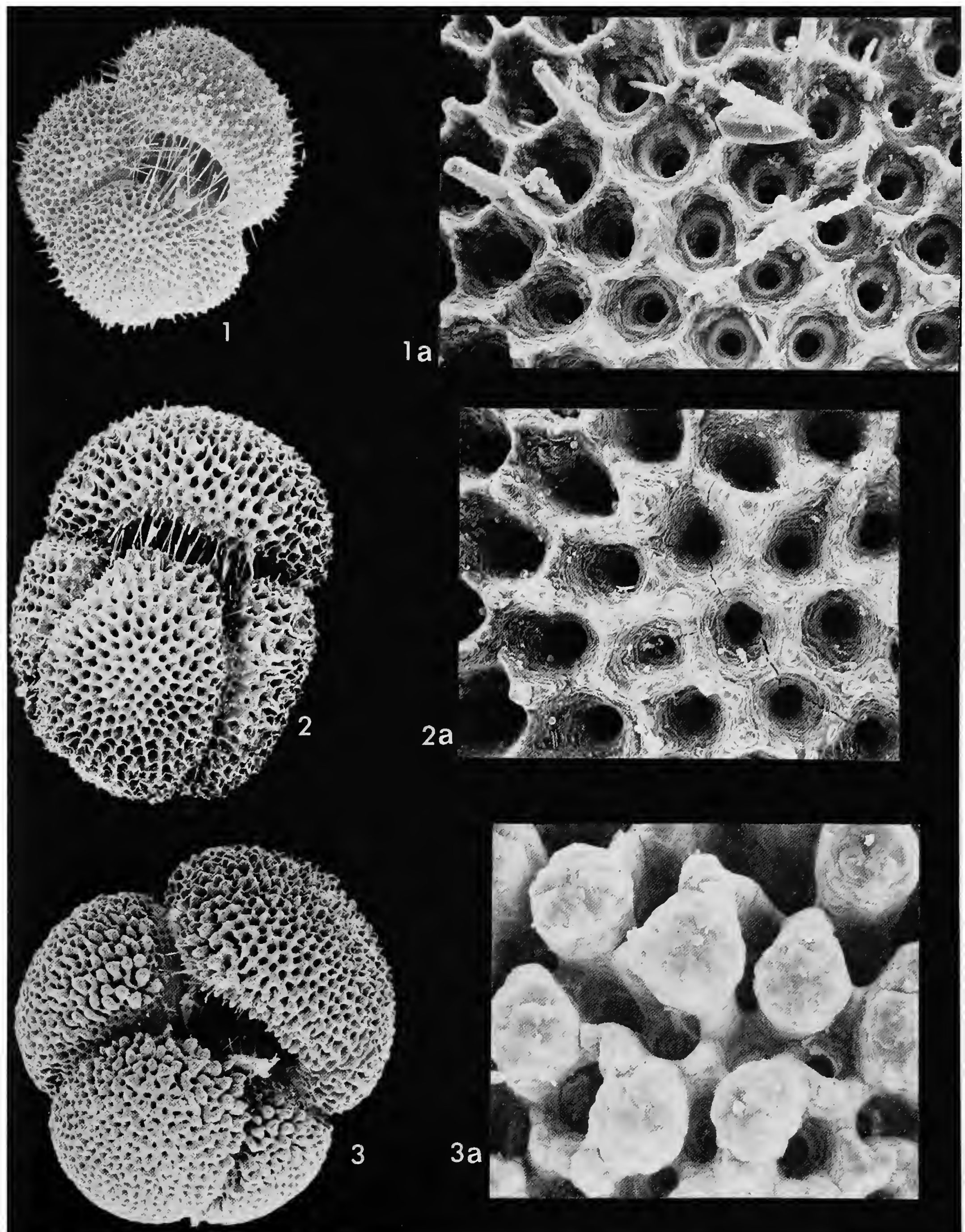


\section{PLATE 8}

1. Globigerinoides conglobatus: Heavily encrusted individual, coarse knobs cover pore areas in earlier chambers; $\times 120$; la, $\mathrm{n}$ chamber, knobs composed of large euhedral, platy crystallites, $\times 1100$. Chain 60-13.

2. Globigerina bulloides: Thin final chamber contrasting sharply with previous ones and appearing imperforate, $\times 110 ; 2 \mathrm{a}$, n chamber partially collapsed, common phenomenon with newly formed chambers of species, pores visible but minute and widely spaced, $\times 800$. Crawford 50-7.

3. Globigerina bulloides: $\times 120 ; 3 \mathrm{a}, \mathrm{n}-2$ chamber, pore ridges weaving irregularly among pores, occasionally enclosing single pore, as in Globigerinoides species, × 1600. Chain 25-462. 


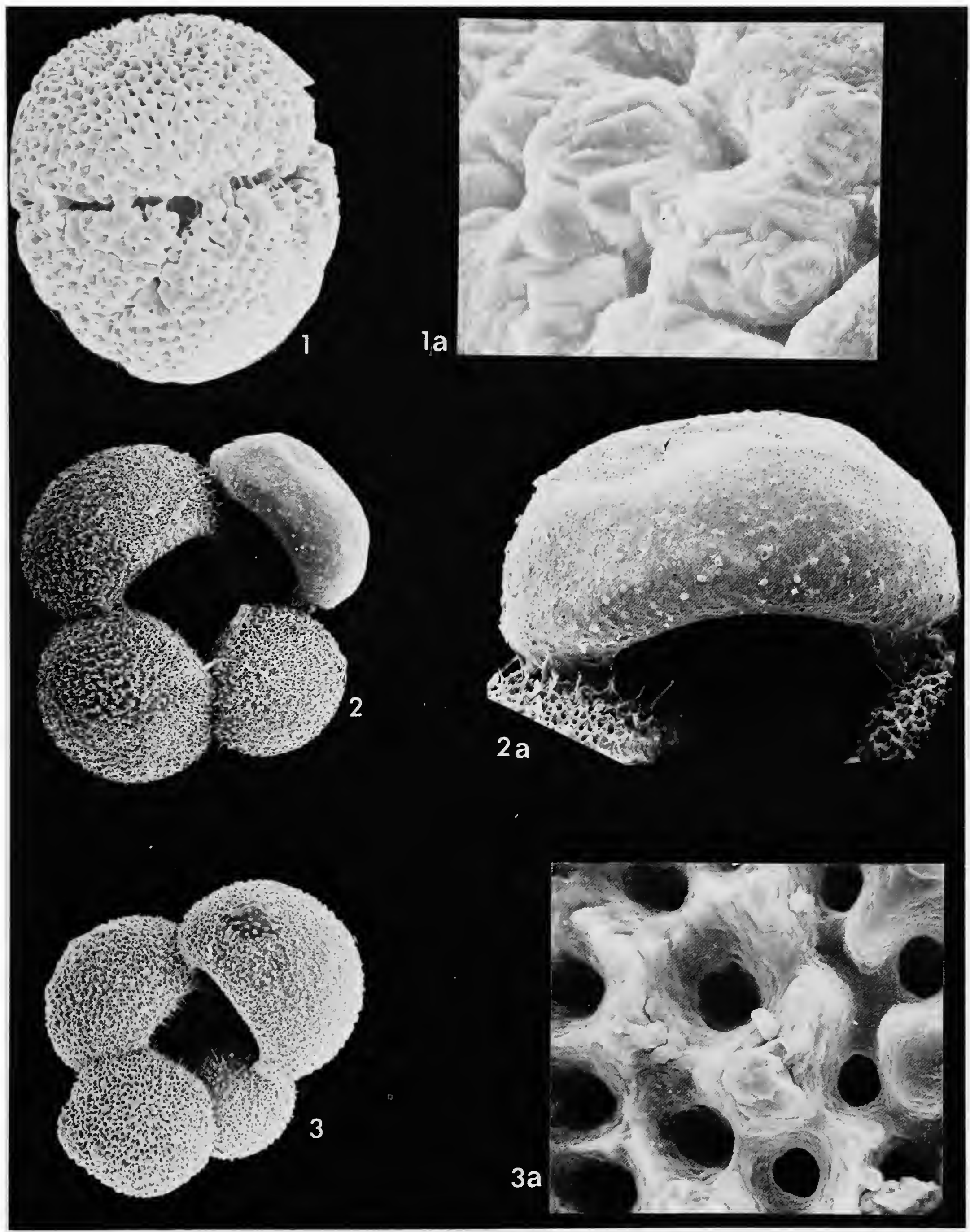




\section{Plate 9}

1. Globigerina bulloides: All chambers relatively mature texturally, pores small and densely packed, $\times 215 ; 1 \mathrm{a}, \mathrm{n}-1$ chamber, ridges developing in sinuous paths among pores, or remaining as isolated heaps among pores, $\times$ 800. Chain $15-7$.

2. Globigerina bulloides: Earlier chambers texturally mature, last chamber newly formed, $\times 160$; $2 \mathrm{a}, \mathrm{n}$ chamber, amorphous heap representing site of spine formation, $\times 2400 ; 2 \mathrm{~b}, \mathrm{n}$ chamber, newly formed spine near top of photo lacking collar, $\times 2400 ; 2 c, n-1$ chamber, sinuous ridges composed of terraced platelets, $\times 2400$. Chain 25-462.

3. Globigerina bulloides: Texture advanced and rather coarse, especially in the earlier chambers, $\times 165 ; 3 \mathrm{a}, \mathrm{n}-2$ chamber, spines discarded, leaving cavities in spine bases, $\times 800$. Chain 25 462 . 


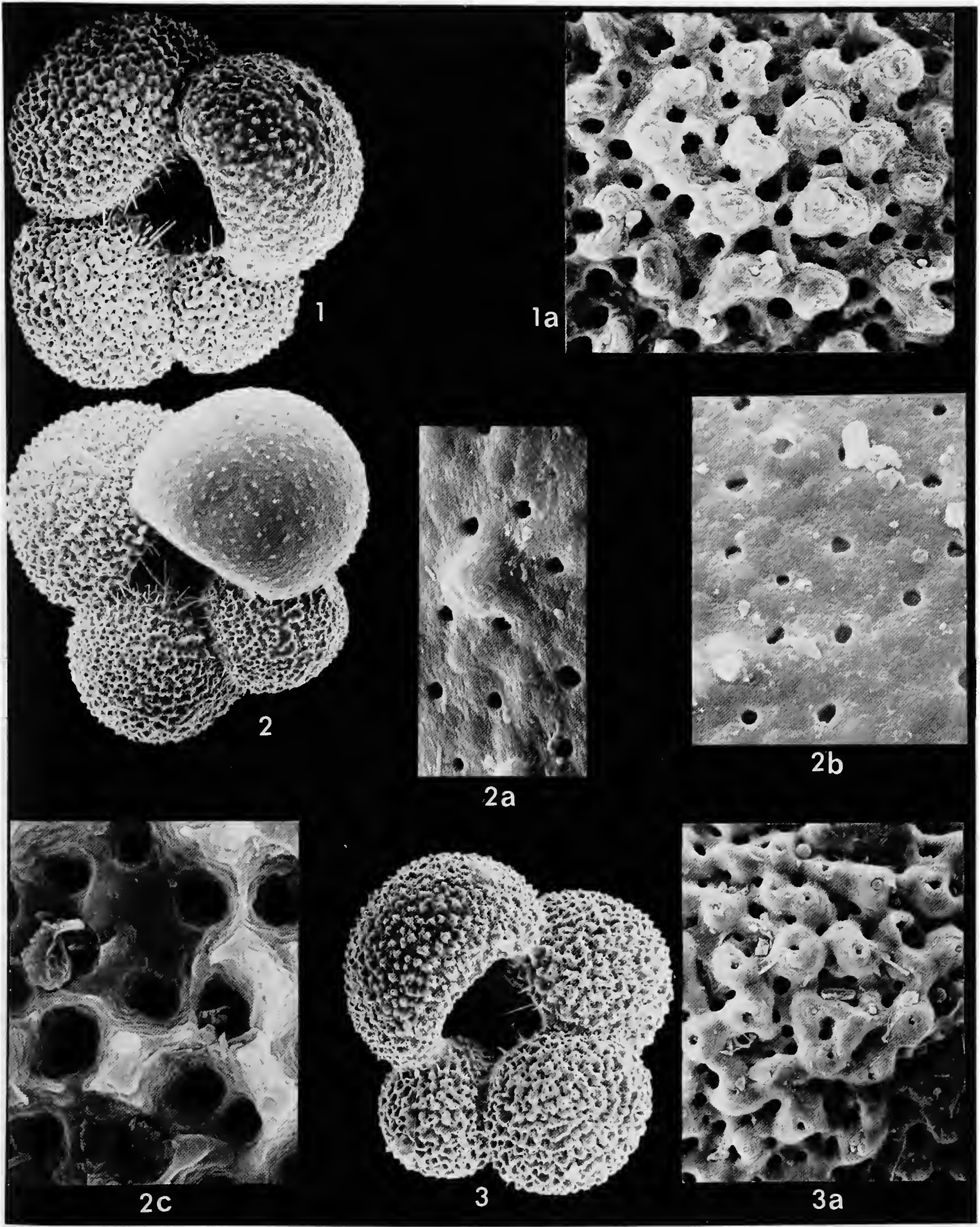




\section{PLATE 10}

1. Globigerina dutertrei: Earlier chambers with moderately well-developed honeycomb structure, final chamber crossed by elongate ridges, resulting in ribbed appearance, $\times 215 ; 1 \mathrm{a}, \mathrm{n}$ chamber, pores large and moderately spaced, ridges tending to run parallel to each other, $\times 1600 ; 1 \mathrm{~b}, \mathrm{n}-2$ chamber, ridges enclosing pores in hexagonal patterns, stunted spines of various sizes irregularly distributed on ridges, $\times 1600$. Atlantis-11-42-42.

2. Globigerina dutertrei: Immature individual with incipient honeycomb structure on earlier chambers, some rib-like pattern of ridges, $\times 240 ; 2 \mathrm{a}, \mathrm{n}-1$ chamber, ridge surface smooth, but with some spine bases at corners of honeycombs, $\times 1600$. Chain 60-16.

3. Globigerina dutertrei: Individual in late stage of calcification with honeycomb structure overgrown by coarse knobs, $\times 100 ; 3 \mathrm{a}$, coarse, rounded knobs concealing pores, $\times 600$. Atlantis-II-42-42. 


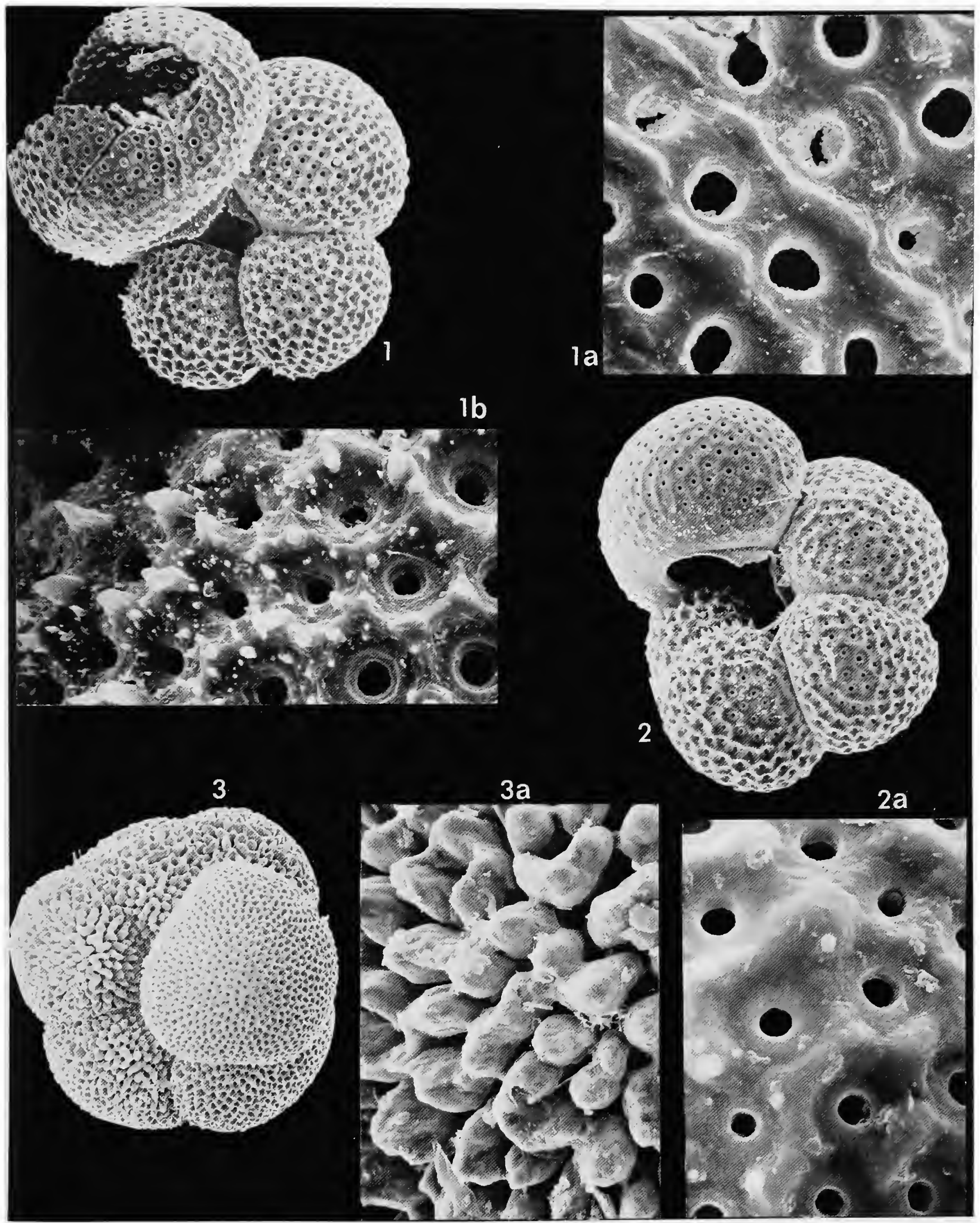




\section{PLATE 11}

1. Globigerina dutertrei: Texturally mature individual, except for final chamber, which has flat surface with elongate subparallel ridges, $\times 120 ; 1 \mathrm{a}$, n chamber, $\times 1200 ; 1 \mathrm{~b}, \mathrm{n}-1$ chamber, each pore surrounded by pore ridges, ridges finely structured but appearing to consist of small platelets, as in Globigerinoides, stunted spines at corners of pore ridges, $\times 800 ; 1 \mathrm{c}, \mathrm{n}-2$ chamber, corriers of ridges bulging, suggesting former presence of spines that have been engulfed by subsequent calcification, $\times 950$. Atlantis-II-42-42.

2. Globigerina dutertrei: $\times 160 ; 2 \mathrm{a}, \mathrm{n}$-chamber, surface flat and crossed by subparallel ridges in lower part of chamber, in upper part an incipient honeycomb structure formed, some stunted spines occupying ridge corners, $\times 800 ; 2 \mathrm{~b}, \mathrm{n}-1$ chamber, ridges surrounding pores, with stunted spines occupying ridge corners, $\times 800$. Atlantis-II-42-42. 


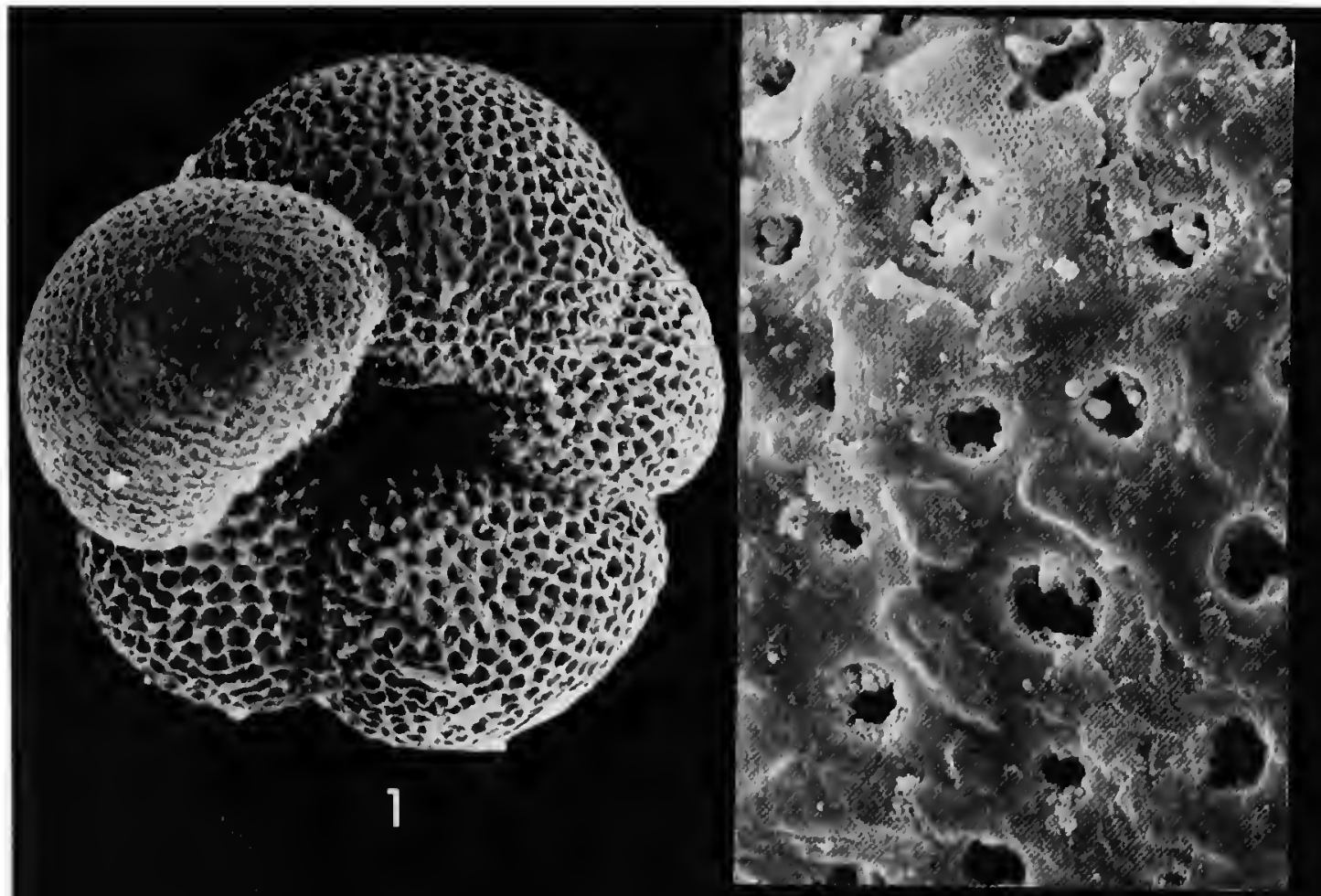

$1 a$

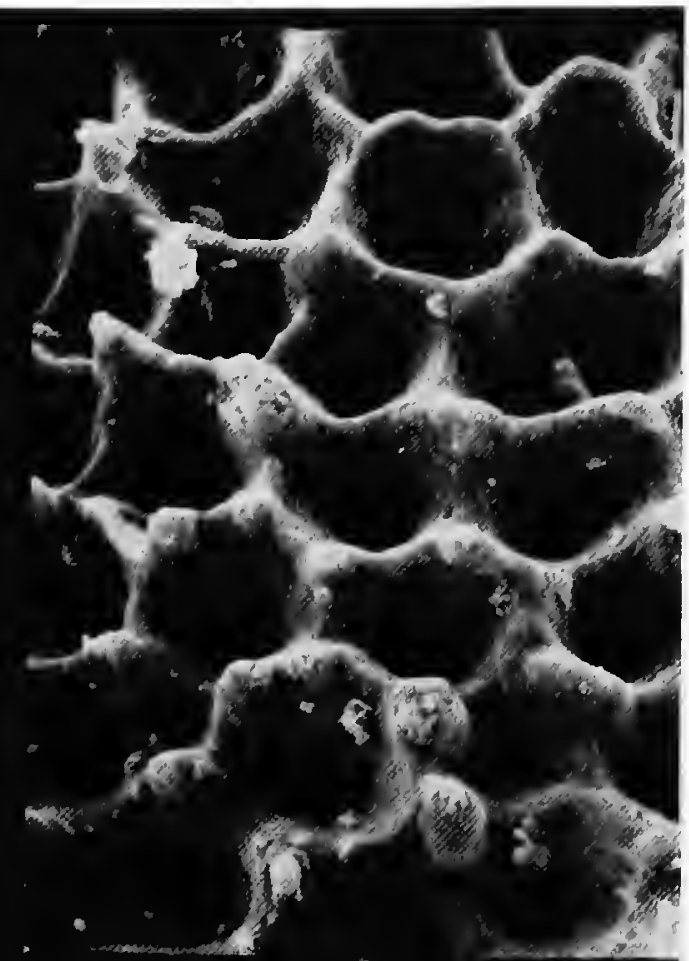

16

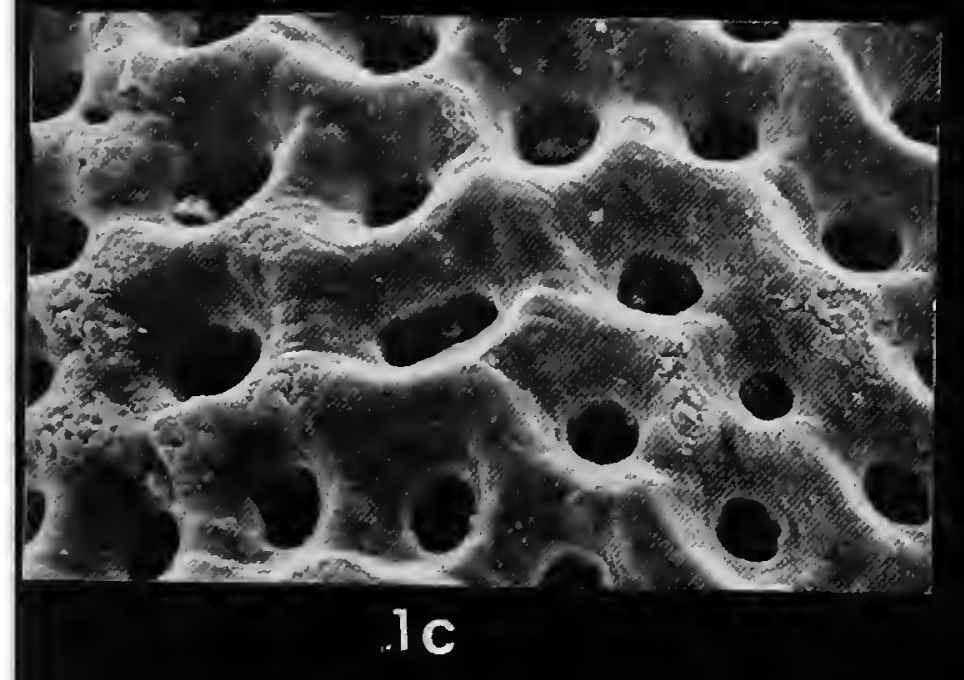

$2 a$

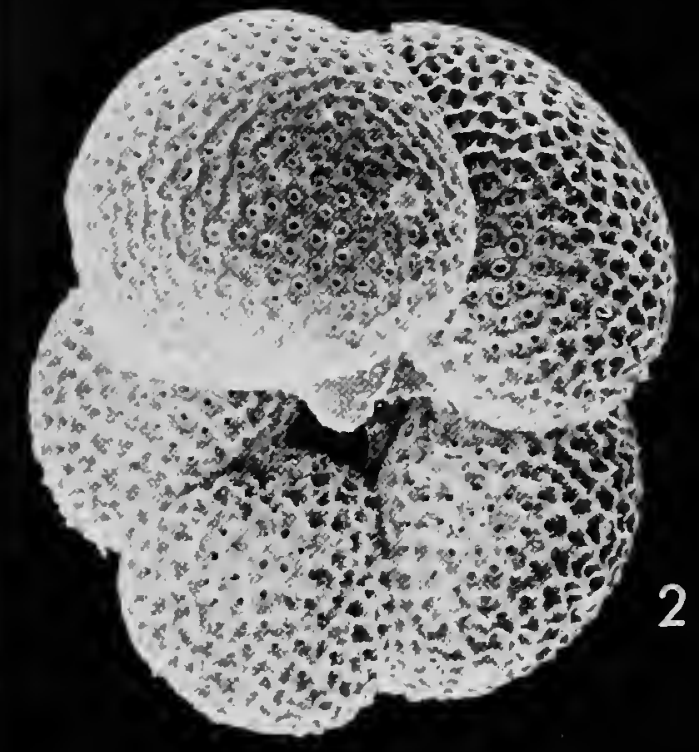

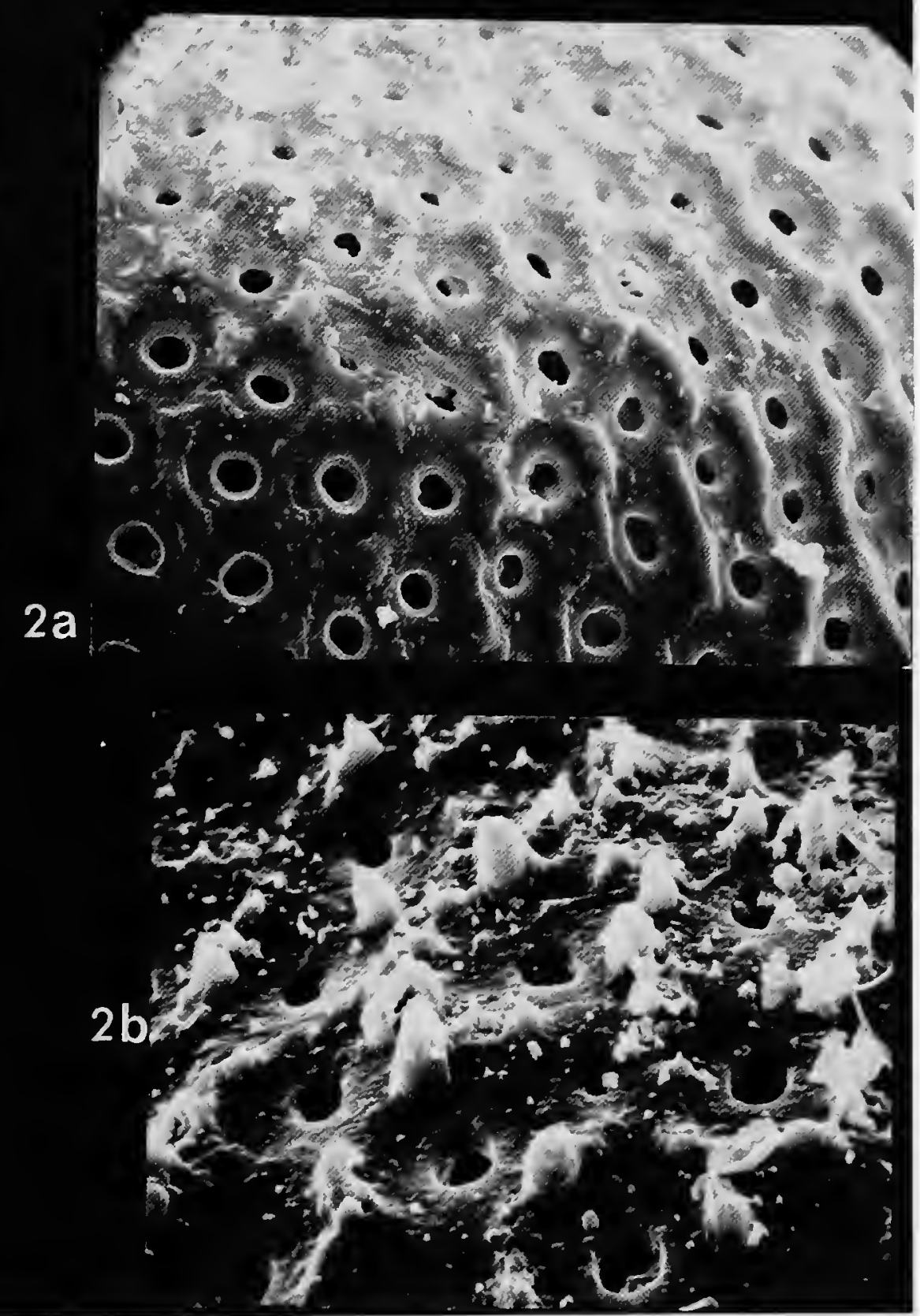




\section{PLATE 12}

1. Globigerina dutertrei: Late, encrusted stage of calcification, most pores in earlier chambers covered by coarse knobs, vestigial honeycomb structure still visible in last two chambers, $\times 135 ; 1 \mathrm{a}, \mathrm{n}-1$ chamber, surface strewn with large euhedral crystals, $\times 1200$. Crawford 42 7.

2. Globigerina pachyderma: Thin-walled but texturally mature form, $\times 240 ; 2 \mathrm{a}, \mathrm{n}$ chamber, ridges showing little tendency to spread laterally and occurring as vertical piles distributed irregularly among pores, $\times 800$. Atlant is-II-32-40.

3. Globigerina pachyderma: Thick-walled form, final chamber with some lateral spreading of ridges, earlier chambers encrusted, $\times 160 ; 3 \mathrm{a}, \mathrm{n}$ chamber, ridges spreading irregularly among pores, $\times 800$; $3 \mathrm{~b}, \mathrm{n}-2$ chamber, pores mostly covered, $\times 800$. Chain $105-8$. 


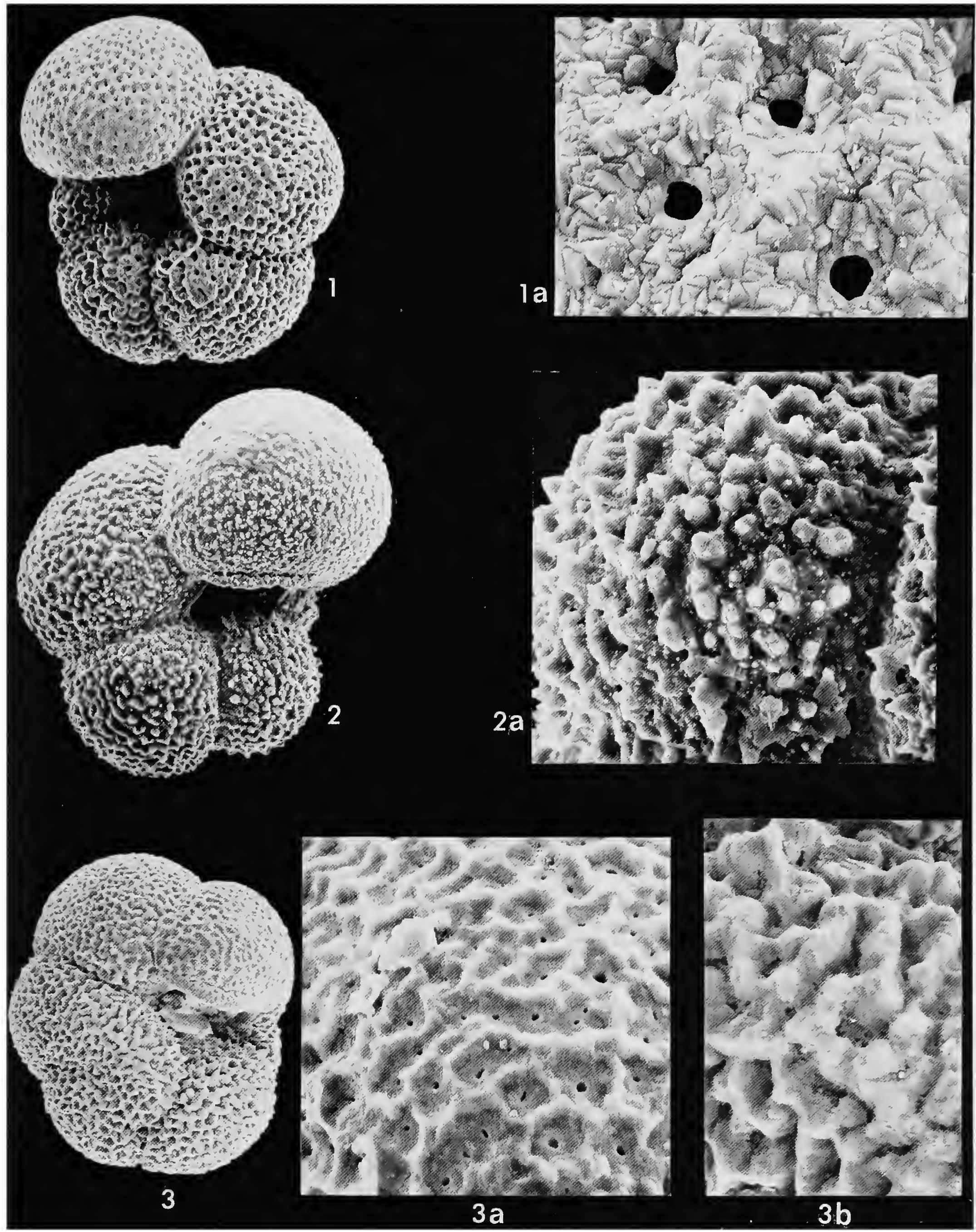




\section{PLATE 13}

1. Globigerina incompta: Texturally immature individual with minute pores and slight ridge-like undulations in earlier chambers, $\times 240 ; 1 \mathrm{a}, \mathrm{n}-1$ chamber, calcite heaps forming incipient ridge patterns and loci for future spine bases around pores, $\times 1600 ; 1 \mathrm{~b}, \mathrm{n}-2$ chamber, multiple spine bases forming around pore areas, granules strewn over surface, $\times 1600$. Atlantis-II-32-30.

2. Globigerina incompla: Texturally mature individual, $\times 190 ; 2 \mathrm{a}, \mathrm{n}-2$ chamber, quasi-honeycomb pattern developed, but pore ridges seldom joined, $\times 1600$. Chain 25-464.

3. Globigerina incompta: Encrusted form, $\times 190 ; 3 a, n-1$ chamber, surface covered with euhedral, platy crystallites, $\times 800$. Atlantis-II-13-26.

4. Globigerina egelida: spine bases appearing as discrete knob-like structures, virtually no development of lateral ridges around pores, $\times 320 ; 4 \mathrm{a}, \mathrm{n}-1$ chamber, spine bases consisting of interlocking grains, $\times$ 2400. Atlantis-II-13-26. 


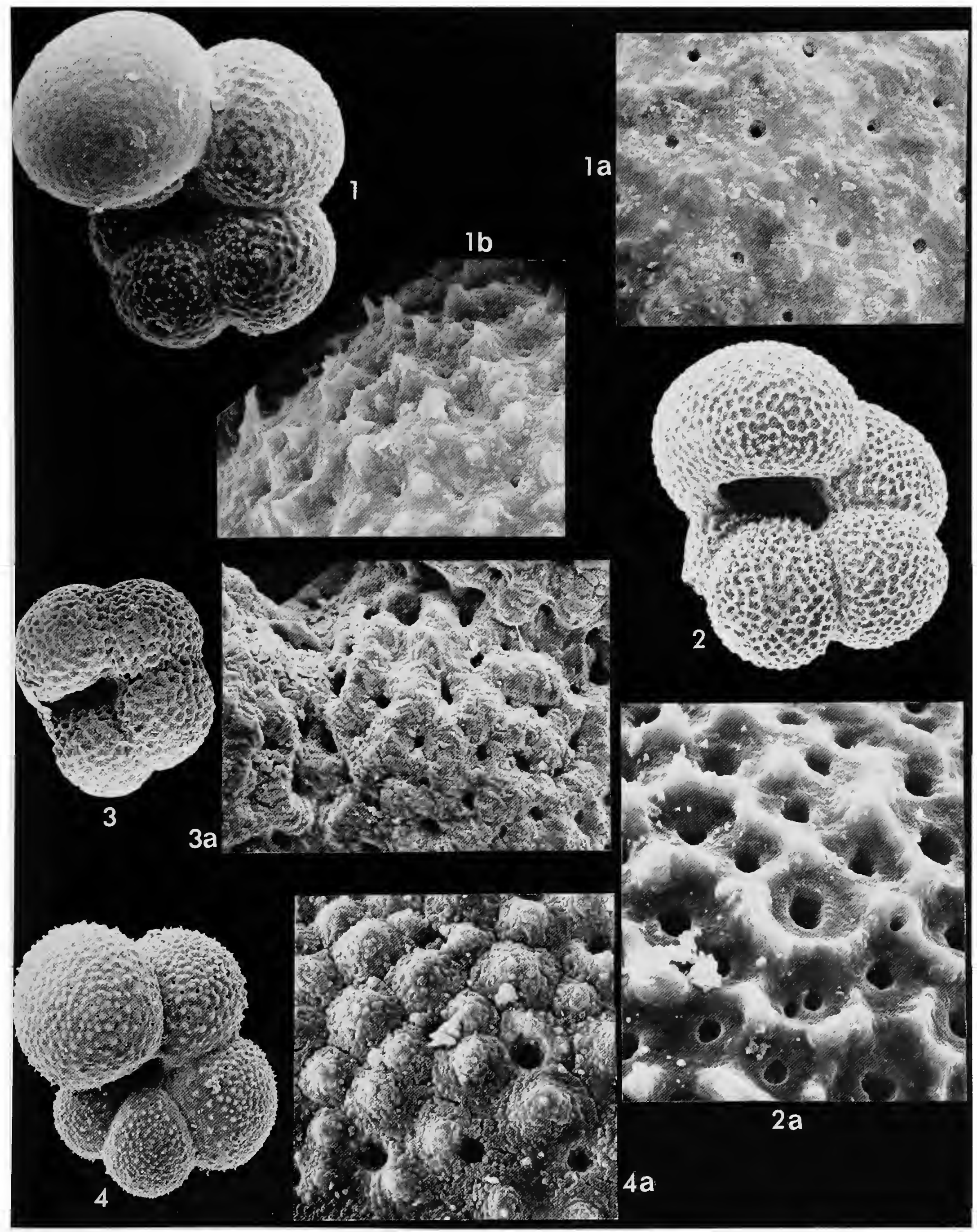




\section{PLATE 14}

1. Globigerinella aequilateralis: Texturally immature individual, chambers, especially final one, thin walled, surfaces flat, $\times 200$. Crawford $42-8$.

2. Globigerinella aequilateralis: Moderately thickened, flat-walled individual, $\times 90 ; 2 \mathrm{a}, \mathrm{n}-1 \mathrm{cham}-$ ber, spine bases distributed erratically among pores over smooth chamber wall, $\times 200$. Chain 25-466.

3. Globigerinella aequilateralis: Quasi-honeycomb texture on all chambers, $\times 140 ; 3 \mathrm{a}$, n chamber, ridges completely enclosing single pores, as in Globigerinoides species and Globigerina dutertrei, $\times 800 ; 3 \mathrm{~b}, \mathrm{n}-6$ chamber, early chambers in penultimate whorl lacking honeycomb texture and remaining smooth, $\times 800$. Crawford $42-7$.

4. Globigerinella aequilateralis: Surfaces flat, on last two chambers, with isolated spine bases, in earlier chambers spine bases more concentrated among pores, $\times 100 ; 4 \mathrm{a}, \mathrm{n}-1$ chamber, spine bases composed of well-formed, terraced platelets, $\times 1600$. Crawford 42-7. 


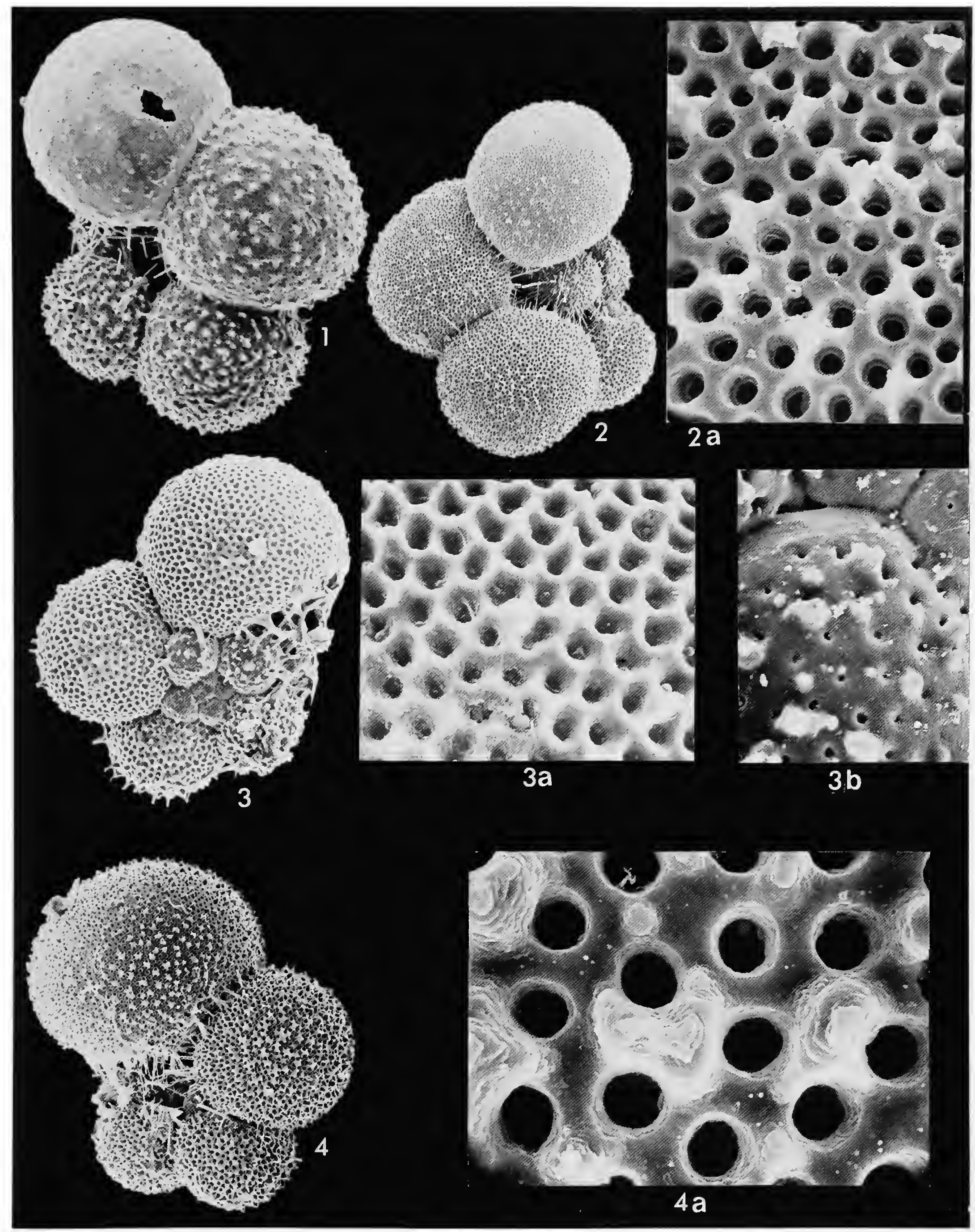




\section{PLATE 15}

1. Globigerinella aequilateralis: Chambers with various stages of calcification, $\times 95 ; 1 \mathrm{a}, \mathrm{n}-2$ chamber, heavily calcified ridges weaving irregularly among pores, $\times 800$; $1 \mathrm{~b}, \mathrm{n}-1$ chamber, moderately calcified chamber, ridges spreading laterally, coalescing and weaving irregularly among pores, $\times 800$. Chain 49-27.

2. Orbulina universa: Wall very flat, with scattered spine bases, $\times 95 ; 2 a$, thin veneer covering surface, beneath veneer, at right side of photo, surface composed of interlocking crystallites, $\times 1600$. Atlantis-II-42-42.

3. Orbulina universa: Thickened individual, $\times 80$; $3 \mathrm{a}$, spine bases buttressed by terraced platelets but platelets not extending laterally into ridges, crystallites strewn over surface, $\times 800$. Chain 17-36. 


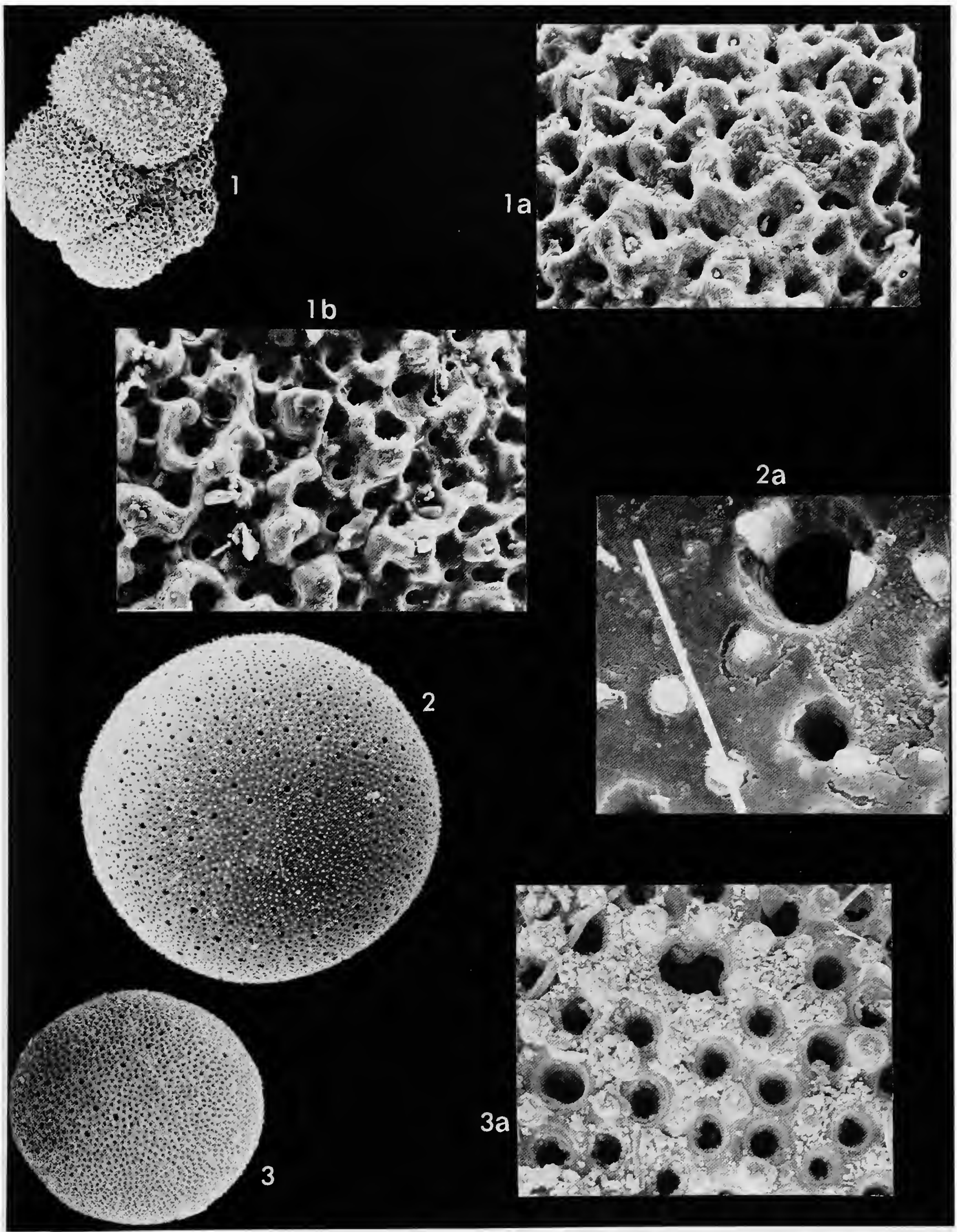







\section{REQUIREMENTS FOR SMITHSONIAN SERIES PUBLICATION}

Manuscripts intended for series publication receive substantive review within their originating Smithsonian museums or offices and are submitted to the Smithsonian Institution Press with approval of the appropriate museum authority on Form SI-36. Requests for special treatment-use of color, foldouts, casebound covers, etc.-require, on the same form, the added approval of designated committees or museum directors.

Review of manuscripts and art by the Press for requirements of series format and style, completeness and clarity of copy, and arrangement of all material, as outlined below, will govern, within the judgment of the Press, acceptance or rejection of the manuscripts and art.

Copy must be typewritten, double.spaced, on one side of standard white bond paper, with $11 / 4^{\prime \prime}$ margins, submitted as ribbon copy (not carbon or xerox), in loose sheets (not stapled or bound), and accompanied by original art. Minimum acceptable length is 30 pages.

Front matter (preceding the text) should include: title page with only title and author and no other information, abstract page with author/title/series/etc., following the established format, table of contents with indents reflecting the heads and structure of the paper.

First page of text should carry the title and author at the top of the page and an unnumbered footnote at the bottom consisting of author's name and professional mailing address.

Center heads of whatever level should be typed with initial caps of major words, with extra space above and below the head, but with no other preparation (such as all caps or underline). Run-in paragraph heads should use period/dashes or colons as necessary.

Tabulations within text (lists of data, often in parallel columns) can be typed on the text page where they occur, but they should not contain rules or formal, numbered table heads.

Formal tables (numbered, with table heads, boxheads, stubs, rules) should be submitted as camera copy, but the author must contact the series section of the Press for editorial attention and preparation assistance before final typing of this matter.

Taxonomic keys in natural history papers should use the alined-couplet form in the zoology and paleobiology series and the multilevel indent form in the botany series. If cross-referencing is required between key and text, do not include page references with in the key, but number the keyed-out taxa with their corresponding heads in the text.

Synonymy in the zoology and paleobiology series must use the short form (taxon, author, year:page), with a full reference at the end of the paper under "Literature Cited." For the botany series, the long form (taxon, author, abbreviated journal or book title, volume, page, year, with no reference in the "Literature Cited") is optional.

Footnotes, when few in number, whether annotative or bibliographic, should be typed at the bottom of the text page on which the reference occurs. Extensive notes must appear at the end of the text in a notes section. If bibliographic footnotes are required, use the short form (author/brief title/page) with the full reference in the bibliography.

Text-reference system (author/year/page within the text, with the full reference in a "Literature Cited" at the end of the text) must be used in place of bibliographic footnotes in all scientific series and is strongly recommended in the history and technology series: "(Jones, 1910:122)" or ".. . Jones (1910:122)."

Bibliography, depending upon use, is termed "References," "Selected References," or "Literature Cited." Spell out book, journal, and article titles, using initial caps in all major words. For capitalization of titles in foreign languages, follow the national practice of each language. Underline (for italics) book and journal titles. Use the colon-parentheses system for volume/number/page citations: "10(2):5-9." For alinement and arrangement of elements, follow the format of the series for which the manuscript is intended.

Legends for illustrations must not be attached to the art nor included within the text but must be submitted at the end of the manuscript-with as many legends typed, doublespaced, to a page as convenient.

lllustrations must not be included within the manuscript but must be submitted separately as original art (not copies). All illustrations (photographs, line drawings, maps, etc.) can be intermixed throughout the printed text. They should be termed Figures and should be numbered consecutively. If several "figures" are treated as components of a single larger figure, they should be designated by lowercase italic letters (underlined in copy) on the illus. tration, in the legend, and in text references: "Figure 9b." If illustrations are intended to be printed separately on coated stock following the text, they should be termed Plates and any components should be lettered as in figures: "Plate 9b.." Keys to any symbols within an illustration should appear on the art and not in the legend.

A few points of style: (1) Do not use periods after such abbreviations as " $\mathrm{mm}$, $\mathrm{ft}$, yds, USNM, NNE, AM, BC." (2) Use hyphens in spelled-out fractions: "two-thirds." (3) Spell out numbers "one" through "nine" in expository text, but use numerals in all other cases if possible. (4) Use the metric system of measurement, where possible, instead of the English system. (5) Use the decimal system, where possible, in place of fractions. (6) Use day/month/year sequence for dates: "9 April 1976." (7) For months in tabular list. ings or data sections, use three-letter abbreviations with no periods: "Jan, Mar, Jun," etc.

Arrange and paginate sequentially EVERY sheet of manuscript-including ALL front matter and ALL legends, etc., at the back of the text-in the following order: (1) title page, (2) abstract, (3) table of contents, (4) foreword and/or preface, (5) text, (6) appendixes, (7) notes, (8) glossary, (9) bibliography, (10) index, (11) legends. 




